\title{
BACK TO WICKSELL? IN SEARCH OF THE FOUNDATIONS OF PRACTICAL MONETARY POLICY
}

Roberto Tamborini 
The Discussion Paper series provides a means for circulating preliminary research results by staff of or visitors to the Department. Its purpose is to stimulate discussion prior to the publication of papers.

Requests for copies of Discussion Papers and address changes should be sent to:

\author{
Dott. Stefano Comino \\ Dipartimento di Economia \\ Università degli Studi \\ Via Inama 5 \\ 38100 TRENTO ITALY
}




\title{
Back to Wicksell? In search of the foundations of practical monetary policy
}

\section{Roberto Tamborini}

University of Trento, Department of Economics, Via Inama 5, 38100 Trento, Italy, roberto.tamborini@economia.unitn.it

\begin{abstract}
It is now widely held that the New Neoclassical Synthesis (NSS) offers central banks a "user friendly", though rigorous, theoretical framework consistent with current practice of systematic stabilization policy based on interest rate rules (e.g. Woodford (2003)). Particular interest and curiosity have been aroused by Woodford's argument that the NNS theory of monetary policy is in its essence a modern restatement and refinement of Wicksell's interest-rate theory of prices (1898). This paper deals with two main issues prompted by Woodford's NeoWicksellian revival. The first questions the consistency between the NNS and Wicksell. The second concerns the value added for monetary policy of Wicksellian ideas in their own right. Section 2 clarifies some basic theoretical issues underlying the NNS and its inconsistency with a proper Wicksellian approach, which should be based on saving-investment imbalances that are precluded by the NNS theoretical framework. Section 3 presents a proper Neo-Wicksellian dynamic model whereby it is possible to assess, and hopefully clarify, some basic issues concerning the macroeconomics of saving-investment imbalances. Section 4 examines implications for monetary policy, in particular for Taylor rules, and section 5 concludes.
\end{abstract}





\section{BACK TO WICKSELL? \\ IN SEARCH OF THE FOUNDATIONS OF \\ PRACTICAL MONETARY POLICY}

\section{Introduction}

Over the last fifteen years the theory and practice of monetary policy (first and foremost in the United States) have been moving along convergent paths to an unprecedented extent (Blinder (1998), Woodford (2003), ch.1). Which side is to be credited for the more valiant effort is open to discussion, but this aspect is of minor importance when compared with the widespread conviction that reviving the consistency between the views of academics and policy-makers is a success story with regard to the ultimate goal of the sound governance of modern market economies. This convergence process has taken place within, and has been prompted by, the advent of what many scholars regard as the newly established macroeconomic consensus: the so-called 'New Neoclassical Synthesis' (NNS) ${ }^{1}$. The key tenets of the NNS can be summarized as follows.

1) Output and employment fluctuate in response to unexpected shocks in the determinants of aggregate demand and supply around a long-period trend of output ("potential output") corresponding to full use of factors up to the "natural rate of unemployment".

2) The economic system responds to shocks with variations in quantities in the short run because of imperfections in the organization of goods and labour markets or because of disincentives by economic agents against price changes.

3) "Money matters": a) Monetary policy impulses have persistent real effects; b) the typical observed pattern is one where policy interventions (mainly activated by changes in administered rates and

1 To mention only few: Goodfriend-King (1997), AEA (1997), Clarida et al. (1999), Blanchard (2000), Woodford (2003). 
money-market rates) are followed by quick and large responses in shortterm interest rates, monetary aggregates, total credit, and different measures of real economic activity, and by slow and delayed adjustment of different price indexes; c) real wages and profits are also procyclical with output after a monetary shock.

4) However, neither fiscal nor monetary interventions on aggregate demand are able to alter the level of potential output and the natural rate of unemployment permanently; their only effect would be to raise the average level of inflation above "core inflation".

5) Economic policy is best managed by means of "rules": policy makers should respond to a stable and transparent objective function such that fluctuations around potential output and core inflation are minimized, without tampering with the "natural" combination of potential output, unemployment and core inflation.

According to Woodford (2003), the NNS now offers central banks a "user friendly", though rigorous, theoretical framework which a) meets the current scientific canons (i.e. those of dynamic stochastic general equilibrium (DSGE) models), b) explains the evidence of real effects of monetary policy, c) grounds the rationale for macroeconomic stabilization on welfare analysis, d) is consistent with the principle of rule-based policy and allows central banks to assess alternative rules of systematic stabilization policy.

Research on the foundations, design and implementation of monetary policy rules is today the most active branch of the NNS (see also Clarida et al. (1999), Taylor (ed.) (1999)). Driven more by successful empirical analyses stimulated by Taylor (1993) and by appeal to the major central banks' modus operandi than by pure theory, this research has focused on interest-rate rules. These rules typically take a short-term interest rate (e.g. the discount rate or the inter-bank overnight rate) as an instrument and describe (or prescribe) how such an instrument should be geared to a set of macroeconomic state variables vis-à-vis their relative target values. To date, Woodford's book offers the most advanced and systematic theoretical foundations of interest-rate rules within the framework of the NNS. His most noteworthy conclusions are 
- interest-rate rules in general ensure determinate macroeconomic equilibria provided that they embody the so-called "Taylor principle", namely that the elasticity of the interest rate to excess inflation should be greater than one

- such macroeconomic equilibria can be ranked according to welfare criteria, and so too can the specification of the underlying interestrate rules

Particular interest and curiosity have been aroused by Woodford's argument that the NNS theory of monetary policy is in its essence a modern restatement and refinement of the kernel of Wicksell's theory as, for instance, set out in his most famous pamphlet Interest and Prices (1898). This renewed "Wicksell connection"2 is, in Woodford's view, substantial because (see e.g. pp. 49-55)

- interest-rate rules imply that the instrumental rate is anchored to the real interest rate that prevails when all macroeconomic state variables are at their target values (e.g. the intercept in the estimated Taylor rules): this real interest rate is best understood as Wicksell's "natural rate of interest", namely the real rate of return to (marginal product of) capital that equals the consumers' marginal rate of substitution along the potential output path

- the Taylor principle also implies that excess inflation arises whenever the instrumental interest rate is below the level consistent with the natural rate, while curbing excess inflation requires the instrumental interest rate to be set above the level dictated by the natural rate: this is precisely the core of Wicksell's theory of inflation and monetary policy .

The alleged Wicksell connection of the NNS has prompted further developments in two main directions. The first is concerned with the consistency of the connection against Wicksell's own theoretical work: recent examples are Boianovsky and Trautwein (2004) and Laidler

2 The reference is to the title of the celebrated paper by Leijonhufvud (1981) which examined the monetary theories of Keynes and the Keynesians in relation to the Wicksellian legacy. As we shall see, this paper is also quite relevant to the Wicksellian claims of the New Keynesians. 
(2004), who argue that Woodford's theory differs from Wicksell's in several essential points, so that they see no substantial reason why the NNS theory of monetary policy should be labelled with the name of the great Swedish economist. The second direction is less concerned with exegesis and seeks to assess the value added of Wicksellian ideas in their own right. In this perspective, Boianowsky and Trautwein subscribe to the point that modern macro and monetary theory still have a lot to learn from Wicksell, and from the Swedish school more generally, but they also stress that the NNS methodological framework of DSGE is alien to the insights of that older mainstream. Interestingly, but not surprisingly, this is in essence the same conclusion that Leijonhufvud (1981) reached in his own assessment of the Wicksell connection at the time of the Old Synthesis, Monetarism and the then raging New Classical Macroeconomics.

This paper deals with both lines of investigation. Section 2 clarifies some basic theoretical issues underlying the NNS and its inconsistency with a proper Wicksellian approach. In fact, the hallmark of the latter is identified in the problem of saving-investment imbalances (i.e. intertemporal dis-equilibria, see Leijonhufvud (1981)) which are precluded by the NNS framework. Section 3 presents a proper "NeoWicksellian" dynamic model whereby it is possible to assess, and hopefully clarify, some basic issues concerning the macroeconomics of saving-investment imbalances. Section 4 examines implications for monetary policy and section 5 concludes.

\section{The New Neoclassical Synthesis, Keynes and Wicksell}

It is apparent that the overall macroeconomic picture provided by the NNS is akin to the Old one that ruled the discipline in the Fifties and Sixties. Indeed, the NNS has grown as a branch of the so-called "New Keynesian Macroeconomics", the research programme launched in the early Eighties and aimed at micro-refurbishing some resilient building blocks of the Old Synthesis, such as price rigidity, the sensitivity of consumption to current income, the investment accelerator, and the 
interest-elasticity of the demand for money (e.g. Greenwald and Stiglitz (1993)). Thus, to some interpreters (e.g. Blanchard (2000)), the evolution from the Old to the NNS may be regarded as an instance of technical progress applied to economic ideas.

It is widely recognized that technical progress has come from the "New Classical Revolution" of the Seventies and Eighties, culminating in the methodology of DSGE based on intertemporally optimizing agents: this is today the established methodology for macroeconomists of all persuasions. Moreover, the NNS now has a clear and consistent counterpart consisting in a Walrasian (New Classical) DSGE. The latter shows how resources would efficiently be allocated by an ideal "frictionless" system of markets. Resources for current production and consumption would be allocated by means of a vector of continuously market-clearing prices. "Potential output" is the aggregate of these resources that would result from the Walrasian price vector. In a simplified economy with homogeneous labour and output, the Walrasian price vector boils down to the relative price of labour, i.e. the fullemployment real wage rate. Intertemporal resources would be allocated by means of a vector of continuously market-clearing capital asset prices. If one assumes homogenous physical capital as well, this vector collapses to a single equilibrium real interest rate, i.e. the real rate of return to (marginal product of) capital that equals the consumers' marginal rate of intertemporal substitution. Potential output, the full-employment real wage rate and the equilibrium real interest rate are pinned down by technology and tastes, and are invariant to changes in the nominal scale of variables.

On the other hand, the New Classicals went too far in their faith in the Walrasian representation of market economies where, apart from "taking the markets by surprise", no consistent foundations could be given to the evidence of real effects of monetary policy, nor to the necessity of monetary policy as a stabilization tool. As was clarified by Hahn (1977) at the very beginning of the New Classical parable, Keynes's fundamental contribution was that there exist some critical 
non-Walrasian features in actual market economies ${ }^{3}$. If not theoretically, these features have proved hard to ignore empirically. Thus, the New Keynesians started investigating a new class of DSGE models in which agents optimize intertemporally in economies with some non-Walrasian features. Of course, the critical question was: what non-Walrasian features? From this standpoint, the NNS has focused on non-Walrasian goods and labour markets, characterized by a) transaction costs, which give rise to a positive demand for money, and b) imperfect competition combined with c) other market imperfections that rationalize short-run nominal wage/price rigidity ${ }^{4}$. Advocates of the NNS argue that the latter was in fact the key non-Walrasian assumption in the General Theory, and far more emphatically, they claim that filtering this assumption through the new methodology has produced successful business cycle models and policy prescriptions that outperform Old Keynesian as well as New Classical ones.

According to Woodford's (2003) systematization of the theory of monetary policy, the NNS microfoundations provide first principles sufficient to explain why the pace of money demand and supply are relevant to the determination of real economic activity. In this framework, non-zero (stock) demand for money (cash) is derived from the household's intertemporal optimization as a complement to demand for the consumption good, while the central bank is the monopolist issuer of the monetary asset. The household's optimal consumption plan thus depends on the entire vector of real interest rates on securities, which can be altered as the central bank changes the opportunity cost of holding money vis-à-vis other assets - this relationship is labelled "IS". Staggered price adjustments under profit maximization implies that

3 Hahn also warned that not all possibile non-Walrasian features are ipso facto classifiable as Keynesians. This is an important remark, to which we shall have to return.

4 Items sub c) are the crucial ingredient in the recipe since imperfect competition by itself does not lead to nominale wage/price rigidity. They range from small menu costs, to staggered contracts, to coordination failures. A good recent survey of these items from this point of view is the one by Van der Ploeg (2005). 
shifts in the IS schedule, whether due to exogenous real or policy shocks, give rise to deviations of output (employment) and prices (inflation) from the respective optimal paths that would prevail with Walrasian markets - this second relationship is labelled PC (Phillips curve), if referred to the labour market, or AS (aggregate supply), if referred to the output market. Finally, the model is closed by an interest-rate rule (IR) that relates the monetary interest rate to deviations of output and prices from their Walrasian paths in such a way that the central bank can stabilize output and prices optimally. This type of three-equations model, with minor variations, is now the workhorse of much applied monetary macroeconomics.

As already noted, the shift of focus from the control of monetary aggregates to the control of monetary interest rates has occurred and has been justified as a technical evolution in the choice of the instrumental variables of monetary policy dictated by innovations in financial markets. After all, the quarrel about the choice between the two types of instruments dates back far into the past: it was acute in the course of the Keynesians-Monetarists controversy (e.g. Moore (1988)), and it is unlikely ever to be settled once and for all. Woodford's own contribution, however, goes further.

In the first place, Woodford endeavours to show that there is more to the choice of interest-rate rules instead of monetary-quantity rules than sheer historical or technical contingencies. To demonstrate this contention, he puts forward his Neo-Wicksellian reinterpretation of the NNS theory of monetary policy on the grounds that Wicksell paved the way for an "interest-rate theory" of the general price level alternative to the quantity-theoretical approach. Thus, drawing on Wicksellian lines, Woodford elaborates his own model of a "cashless and frictionless" economy (ch. 2), the purpose being to show that, even in a world "where the concepts of money demand and supply become inapplicable" (p. 49), the central bank can still control the inflation rate by setting the interest rate on "base money". In this model, base money is a riskless security that exchanges 1 to 1 units of account in all states in an Arrow-Debreu economy with complete asset markets where transactions are settled 
without actual currency exchanges by, say, a central computer that stores individuals' book entries in a common unit . Asset pricing (interest rates determination) is derived from the representative household's intertemporal optimization and the usual no-arbitrage condition. Note that the model does not preclude the existence of other riskless securities competing with base money. Nonetheless, Woodford claims that the model demonstrates that

- the central bank can freely set the nominal interest rate on base money,

- arbitrage keeps all other market rates (real rates corrected for expected inflation) aligned with it, and

- given the market real rates, the central bank can thus determine the general price level of goods by acting as a "manager of expectations" (e.g. pp. 50-53).

The key arbitrage condition is nothing but the Fisher's equation, which for 1 year maturity and zero risk premium Woodford writes as ( $p$. 50)

$$
i_{t}=r_{t}+\left[\mathrm{E}_{t} p_{t+1}-p_{t}\right]
$$

where $i_{t}$ is the nominal interest rate on base money, $r_{t}$ is the real market interest rate, or Wicksell's "natural rate of interest", $p_{t}$ is the log of the general price level and $\mathrm{E}_{t}$ is the expectation operator conditional on information at $t$. Given $p_{t}$ and $i_{t}$, there is only one path of future expected prices consistent with the above condition.

Woodford presents this part of his treatment of the NNS as a thought experiment that, abstracting from the imperfections assumed in the standard NNS framework, may simplify the analysis of the foundations of monetary policy and may give logical strength and generality to the optimality of interest-rate rules (p. 32). Since Woodford's "cashless and frictionless" economy apparently has no nonWalrasian features, at first sight one wonders whether he is taking us back to a chimerical Walrasian world with money (or, even more remarkably, without money but with a monetary authority). Indeed, as shown by Boianovsky and Trautwein (2004), it is hard to find in Woodford's model a convincing explanation as to why anybody would 
hold non-zero stocks of base money (which are however forced into the household's budget constraint) or any consistent proof of the central bank's ability to set an independent interest rate on base money if its stock happens to be positive ${ }^{5}$.

Whether or not Woodford's thought experiment is successful, one may concede that it is not an essential part of his Neo-Wicksellian reinterpretation of the NNS theory of monetary policy. Nevertheless, the problems that surface in the "cashless and frictionless" model can also be detected in the subsequent parts where transaction costs and staggered price adjustments are reintroduced (see also Goodhart (2004) and Laidler (2004)). The problem that concerns me here is not so much the Wicksellian (un)faithfulness of Woodford's model as whether a truly Wicksellian approach may improve our understanding of business cycles and of the role of monetary policy. To begin with, however, it is necessary to point out at least the key points on which Woodford differs from Wicksell.

5 The basic logical problem raised by Woodford's model is clear in his arbitrage equation. Is it expected inflation (in square brackets) that responds to independent changes in $i_{t}$ or the other way round? Equilibrium asset pricing implies that all assets in the same risk class should strike the same price (interest rate) and no issuer can freely set the price (interest rate) of its own asset. Woodford's argument that "the special feature of central banks is simply that they are entities whose liabilities happen to be used to define the unit of account in a whole range of contracts that other people exchange with one another" (p. 37) is far from convincing. If a common unit of account is used, say "euro", then all securities are denominated in euros and promise a certain (state-contingent) amount of euros that accrue to the holder's electronic account. There is no way in which the central bank's security can be distinguished from other equally riskless securities, and hence there is no way in which the ECB can freely set its own interest rate, forcing the other market rates to realign by means of arbitrage. Therefore, the only consistent interpretation of Woodford's arbitrage condition is that "a central bank can have no effect on nominal interest rates except insofar as it can shift inflation expectations" (p. 139). Hence, starting from equilibrium, the ECB would only be allowed to raise its own interest rate today to the extent that this gives rise to the (rationally expected) increase of next year's price level. But this is "quite contrary to the original Wicksellian story (not to speak of reality)" (Boianovsky and Trautwein (2004), p.9). 
1) Wicksell's interest-rate theory of price determination was elaborated not with reference to continuous intertemporal equilibrium of households' asset stocks but as a development of a number of crucial aspects of money creation and circulation that were apparently unaddressed by the then dominant quantity-theoretic equation. In other words, Wicksell adopted not a stock approach but a flow approach to monetary analysis (Leijonhufvud (1981), Laidler (2004), Boianovsky and Tratutwein (2004)).

2) One crucial aspect introduced by Wicksell was bank intermediation, which is also notably absent from Woodford's work. Indeed, in Wicksell's book the fiction of a cashless economy appears in the context of a "pure credit economy" (see also Goodhart (2004) and Laidler (2004)). The ingenious function of the cashless fiction was to separate the problem of the control of money creation from its role as physical means of payment. Yet Wicksell's economy "is not a moneyless economy" (Laidler (2004), p.3) in that the key problem to be explained remains how a single agent can have his/her virtual account - i.e. his/her nominal purchasing power in number of "euros" - increased. Apart, of course, from selling goods and services, the only other way for an agent to increase his/her nominal purchasing power is to borrow. Consequently, the appropriate concept of money demand is the one expressed by borrowers, whereas the appropriate concept of money supply is the one expressed by lenders.

3) In Wicksell's "pure credit economy", borrowers are investing firms and lenders are saving households, intermediated by banks. As long as non-bank agents borrow and lend one with the other, the total amount of nominal purchasing power in the economy is redistributed but cannot (need not) increase. The capital market finds its equilibrium at the natural rate of interest as determined by the "forces of productivity and thrift" that equate saving and investment at full-employment of resources. Yet, as soon as the banking system (central bank and private banks) comes into play, the latter proposition no longer necessarily holds. A private bank is in a position to grant additional nominal purchasing power to any of its depositors' accounts with no one else in the economy 
undergoing an equivalent reduction. And likewise a private bank can increase its own nominal purchasing (lending) power by borrowing from the central bank. Thus, the problem is that the banking system as a whole might both expand the total nominal purchasing power in the economy and allocate it at terms that differ from those dictated by fullemployment saving-investment equilibrium.

4) Wicksell's economy is not a "frictionless economy" at all. First, there are intermediaries between savers and investors, whose existence can only be due to some frictions relative to the Walrasian benchmark. Second, all three actors on the capital market act with limited information, which may be responsible for deviations of the market interest rate from the natural rate, as well as for the ensuing dynamics of money creation, income and prices - the well-known "cumulative process" (Leijonhufvud (1981), p.160). In this framework, the connection between money creation and nominal income is necessarily examined in its out-of-equilibrium dynamics from one level of money and nominal income to another:

In Wicksell's theory of the cumulative process, the maladjustment of the interest rate - the discrepancy between the market and the natural rate - is the central idea. It is also the idea that motivates the analysis of changes in the price level (or in nominal income) in terms of saving and investment. It is a simple but fundamental point. Use of the saving-investment approach to income fluctuations is predicated on the hypothesis that the interest rate mechanism fails to coordinate saving and investment decisions appropriately. This is where all the Wicksell Connection theories differ from Monetarism (Leijonhufvud (1981), p.132).

Leijonhufvud's last sentence also applies perfectly to Woodford's renewed attempt at a connection with Wicksell. Monetarism was developed on the grounds of continuous capital-market clearing in terms of asset stock equilibrium, farther and farther away from Wicksell's macroeconomics of saving-investment imbalances 6 . This line of theorizing has then been systematized and popularized in the DSGE

6 Not without the complicity of the liquidity preference theory of the interest rate and of Keynesians themselves, according to Leijonhufvud. 
methodology. As explained above, the NNS has fully embraced this methodology, though introducing the non-Walrasian features able to breathe new life into the monetary side of these models. Long-standing doubts and criticisms about whether these features are truly Keynesian, and whether they are necessary and sufficient to understand and master business cycles, are still unresolved (e.g. Van der Ploeg (2005)). Other scholars of Keynesian inspiration would instead stress the central role of saving-investment imbalances in the General Theory as well, and would therefore focus on different non-Walrasian features: in particular, those impinging upon financial markets and leading to intertemporal coordination failures (e.g. Minsky (1975), Leijonhufvud (1981), Greenwald and Stiglitz (1993), Solow and Hahn (1995)). Common to these views, though different in other methodological respects, is the idea that the older macroeconomics of saving-investment imbalances does offers guidance for consistent foundations of the interest-rate theory and practice of monetary policy precisely because it focuses on the interest rate as "the wrong price" in the system and lead us to investigate how the monetary authority can manage to 'get it right'.

\section{A Neo-Wicksellian model}

In this section I introduce a simple Neo-Wicksellian model, by which term I mean a model where,

- there exists a level of the real interest rate, the "natural rate", whereby the economy rests in a steady state characterized by a given level of "potential output" and a constant "core inflation rate"

- fluctuations of output and inflation occur as dynamic (out-ofequilibrium) adjustment processes following nominal or real shocks as long as the market real interest rate diverges from the natural rate

- the nominal interest rate responds to some measure of the inflation rate and possibly to other macroeconomic state variables

The steady-state benchmark of the economy in terms of output, employment and inflation can be traced back to the competitive generalequilibrium allocations with fully flexible price and full use of resources. 
Alternatively, the steady state can be characterized by an equilibrium real wage rate such that a non-zero "natural rate of unemployment" exists, to which a lower "potential output" corresponds. The difference is immaterial here. The point is that the price vector along the intertemporal general-equilibrium path of the economy includes the relative price of factors (the real wage rate and the natural interest rate), and the problem is how the economy reacts when the "wrong" price is the interest rate.

Suppose a shock occurs at time $t$ such that the market real interest rate exceeds the natural one. Excess saving arises to which there corresponds excess supply in the goods market at time $t$, and, by intertemporal Walras Law, excess (planned) demand at time $t+1$. Excesses can only be eliminated by a combination of lower saving/higher investment at time $t$ and/or lower (than planned) consumption/higher (than potential) production at time $t+1$. To this effect, it is required either a fall in the market real interest rate at time $t$, or a combination of rise of inflation/rise of unemployment at time $t+1^{7}$. Note that the capital-market disequilibrium at time $t$, if uncorrected, must have an intertemporal disequilibrium effect on the goods (and labour) market at time $t+1$ even though goods prices (and wages) are perfectly "right" with respect to the natural interest rate. Consequently, as thoroughly explained by Leijonhufvud (1981), there are, or should be, two key logical implications of any Wicksellian (and, for that matter, Keynesian) model, namely

- "unemployment will not converge to its natural level unless the interest rate goes to its natural level - (...) the latter condition will not always be fulfilled" (p. 135)

- "with the interest rate at the right level, market forces should make unemployment converge to the natural rate - otherwise not" (p.136) 8

7 An anticipated rise of inflation at time $t+1$ is of course a means to reduce the real interest rate at time $t$.

8 To put it differently, that the relative price of factors, and the relative markets, should in some way be interconnected is pure general-equilibrium theory until Keynes (included). This point apparently fell by the wayside in the Old Synthesis, and then in modern macroeconomics altogether. Friedman still made the point (the natural rate of unemployment is the rate observed at the 
To formalize these propositions, one needs a dynamic model, not in the current sense of the path of continuous intertemporal equilibrium, but in the sense that it should track the behaviour of the system out of equilibrium in the transition from one steady state to another. An example drawn from the standard IS-AS framework of current macroeconomics (see e.g. Woodford (2003), ch.4, par. 2.2) is the following. Let $y$ denote potential output, determined by tastes, technology and the intertemporal equilibrium price vector; these data identify $y$ as a point on the IS schedule of the economy. Also let potential output be associated with the core inflation rate $\pi$ and a non-zero rate of unemployment $u$ (NAIRU). These data identify a point on the (vertical) PC schedule of the economy. Let then the dynamics around these schedules be described as follows:

$$
\begin{aligned}
& y_{t+1}=(1-\rho) y+\rho y_{t}-\alpha\left(i_{t}-\pi_{t+1}^{e}-r\right) \\
& \pi_{t+1}=\pi+\beta\left(y_{t+1}-y\right) \\
& \pi_{t+1}^{e}=\pi_{t+1}
\end{aligned}
$$

Equation (1) describes the dynamics around the IS schedule as the actual output $y_{t}$ deviates from its potential level $y$ triggered by deviations of the market real interest rate $\left(i_{t}-\pi_{t+1}^{e}\right)$ from the natural rate $r$ with some degree of persistence $\rho$. It should be borne in mind that, as explained above, IS disequilibrium implies that output gaps are associated with inverse unemployment gaps at the equilibrium price vector. Equation (2) describes the associated price dynamics around a vertical Phillips curve pegged to the core inflation rate $\pi$, where unemployment dynamics is replaced with the corresponding output gaps to obtain a dynamic $\mathrm{AS}^{9}$. The model is closed by the determination of the expected inflation rate that enters the real interest rate. In the context of

natural rate of interest) in his "Presidential Address" (1969, p.8), but it apparently went unnoticed. Thus, as explained by Dixon (1995), modern macroeconomics is based on ad-hoc assumptions such that the labour market has been "decomposed" from the rest of the system, notably from the capital market.

9 Alternatively, equation (2) can be obtained directly via firms' optimal production plans either under perfect competition and unanticipated inflation or imperfect competition and staggered price changes. 
this model, the rational expectations hypothesis would imply that agents know the steady-state values of the variables, which in turn depend on the inflation expectation itself. This is the notorious self-referentiality inherent in the rational expectations hypothesis (see e.g. Evans and Honkapohja (2001)). I introduce a less demanding and problematic hypothesis, namely "short-run" rational expectations, that is the correct forecast of one-period-ahead inflation during the adjustment process as reproduced by equation (3).

First of all, note that equations (1)-(3) form a system of first order difference equations. The steady-state values of the vector of the endogenous variables $\left[y_{t}, \pi_{t}\right]$ are

$$
\begin{aligned}
& \bar{y}=y \\
& \bar{\pi}=\pi
\end{aligned}
$$

if and only if

$$
\bar{i}=r+\pi \equiv i
$$

Expression (6) is the "non-accelerating-inflation rate of interest" (NAIRI) that equals the natural rate plus core inflation. The key point is, as required, that potential output, the NAIRU and the NAIRI should hold simultaneously for the system to be in steady state and for the endogenous variables to take their theoretical values (4)-(5). The point can be seen in detail on considering the output-gap dynamic equation obtained from equations (1)-(3), i.e.:

$$
y_{t+1}-y=\rho^{\prime}\left(y_{t}-y\right)-\alpha^{\prime}\left(i_{t}-i\right)
$$

where

$$
\rho^{\prime} \equiv \frac{\rho}{1-\alpha \beta}, \alpha^{\prime} \equiv \frac{\alpha}{1-\alpha \beta}
$$

Provided that $\rho<(1-\alpha \beta)$, output settles at $y$ only if $\left(i_{t}-i=0\right)$. I shall call the latter the "interest rate gap".

Though simple, this model is able to reproduce the effects of various types of shocks, namely, real shocks to the NAIRI $i$ (i.e. shocks to the natural rate of interest), nominal shocks to the market interest rate $i_{t}$, inflationary shocks to the core inflation rate $\pi$, real supply-side shocks to potential output $y$. 
Let us now move to the determination of the nominal interest rate. As explained above, this should consist in an adjustment equation of the nominal interest rate $i_{t}$ that endogenizes the dynamics of the interest rate gap after an initial shock. For the sake of comparison, and to prepare for discussion of monetary policy rules, I first consider three different specifications inspired by alternative theories of the interest rate: 1) a Wicksellian bank mechanism, 2) a "dynamic" Keynesian LM equation, 3) a "speculative" LM equation. All three specifications relate to market forces driving the nominal interest rate, with no explicit role for any monetary authority. I shall then move to monetary policy by examining different versions of the Taylor rule.

For each specification, I present simulations of the model, mainly under real and nominal shocks to the NAIRI. All the variables have been treated as index numbers, and their initial steady state values normalized to 100 . The parameters have been set to the following values:

$$
\rho=0.1, \alpha=0.3, \beta=0.5
$$

Of course, these values have no particular empirical meaning, but they portray a system where persistence is low, interest rate gaps have a moderate effect on output, and output gaps have a limited effect on the inflation gap or prices are sticky ${ }^{10}$. These parameters also ensure that, as long as the interest-rate gap is nil, equation (7) is stable. In other words, we do not want the system to be unstable by assumption; rather, we want to understand under what conditions different interest-rate adjustment mechanisms contribute to stability or not.

\subsection{The Wicksellian bank mechanism.}

The well-known Wicksellian idea is that the out-of-equilibrium nominal interest rate is procyclical with economic activity and the price level. The explanation is that this process is driven by the need of banks to keep their accounts balanced during the expansion (contraction) of the

10 Yet, as is clear from the model's structure, this not the cause of out-ofequilibrium dynamics. The parameter $\beta$ only splits the IS fluctuations, induced by interest-rate gaps, between output and prices. 
demand for funds and of the price level ${ }^{11}$. As explained in section 2 , this mechanism hinges on a limited informational requirement, in that banks need not know what the natural rate is at each point in time, which is consistent with the idea that the nominal interest rate may assume wrong values ${ }^{12}$. Conversely, firms do know what the natural rate is, so that they raise or cut their demand for funds as long as the bank interest rate is misaligned. Wicksell and his followers also attached great importance to inflation expectations. Being aware that the system's steady state should display a constant price level (or inflation rate), the problem was what inflation rate agents would expect over the disequilibrium "cumulative process" (see e.g. Leijonhufvud (1981), Tratuwein and Boianovich (2004)). The first hypothesis to examine is that agents believe in a "normal" inflation rate to which the economy tends. Let this belief be $\pi$, consistently with the inflation structural process (2). Therefore, the resulting representation of the Wicksellian bank mechanism is the following:

$$
i_{t}=i_{t-1}+\gamma\left(\pi_{t}-\pi\right)
$$

that is to say, the nominal interest rate goes on rising (falling) as long as inflation accelerates (decelerates) with respect to the core rate $\pi$.

On adding this equation to system (1)-(3), the steady-state values of the endogenous variables are $\bar{y}=y, \bar{i}=i, \bar{\pi}=\pi .{ }^{13}$ As to convergence and stability of the system, it is interesting to restrict our analysis to monotonic convergence conditions ${ }^{14}$. For an interest rate mechanism associated with oscillations of the system, even though convergent, would

11 For an abridged version of his theory see e.g. Wicksell (1907).

12 Apparently, the Fisher equation provides an analogous mechanism that may relate the market interest rate to inflation, but there is an important underlying difference, which is immediately brought to light by this exercise. The Fisher equation holds in steady state as shown by expression (6), but we cannot use it consistently as an out-of-equilibrium mechanism because it would imply that the market instantly adjusts the market interest rate to the NAIRI at each point in time. Therefore, there would never be any interest rate gap!

13 All proofs in Appendix

14 A stable system with monotonic convergence requires its characteristic equation to have all real positive roots smaller than 1. 
neither be interesting nor recommendable. In the present case, for any $\gamma$ $>0$, the following single condition is sufficient 15

$$
\gamma<\frac{1+\rho^{\prime}-2 \rho^{\prime 1 / 2}}{\alpha^{\prime} \beta}
$$

This result shows that the Wicksellian mechanism is stabilizing only within a given range of the sensitivity of the nominal interest rate $\gamma$ to inflation dynamics, namely 2.45 with our parameters. The economic meaning of this condition can be understood by noting that $\gamma \alpha$ ' $\beta$ measures how much one point of interest-rate gap is self-corrected through the response $\gamma$ of the interest rate to the inflation gap $\beta$ generated by the output gap $\alpha$. As is intuitive, a stabilizing adjustment mechanism requires that $\gamma$ should be smaller, the larger are $\alpha^{\prime}$ and $\beta$. As $\gamma$ increases, the system first takes an oscillatory path and then becomes unstable. Provided that condition (9) holds, despite the NAIRI $i$ is not made explicit in the interest-rate equation, the nominal interest rate does converge to that value.

I now report the results of the two typical instances in the Wicksellian literature: A) a permanent real shock to the NAIRI, B) a temporary nominal shock to the bank interest rate. The parameter $\gamma$ has been set equal to 0.5 , which satisfies condition (9).

15 Proof: see Appendix A1. 
A) Permanent real shock to the NAIRI ( $r$ falls up to 10 basis points of interest rate gap at time 0 and forever (new NAIRI $=90$ ); $\pi, y$ held constant $=100$ ).

Figure 1. Time diagram

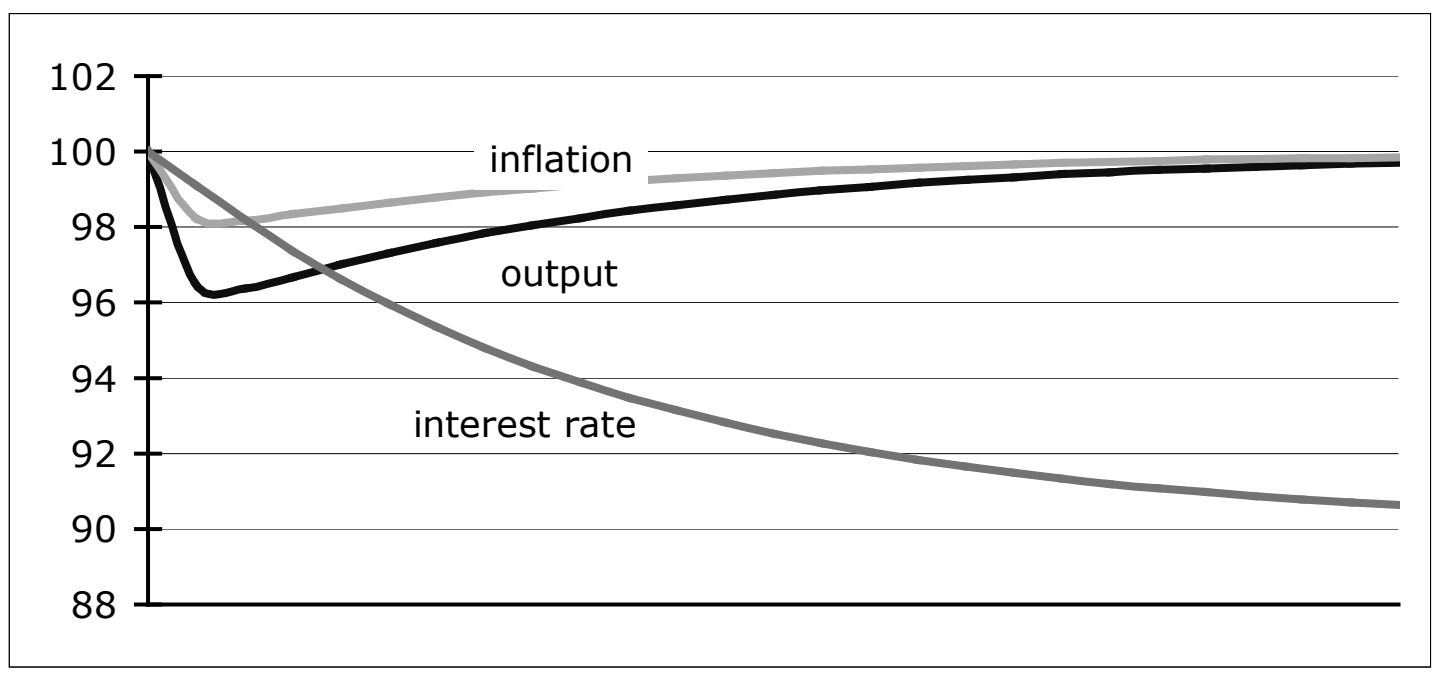

Figure 2. AS diagram

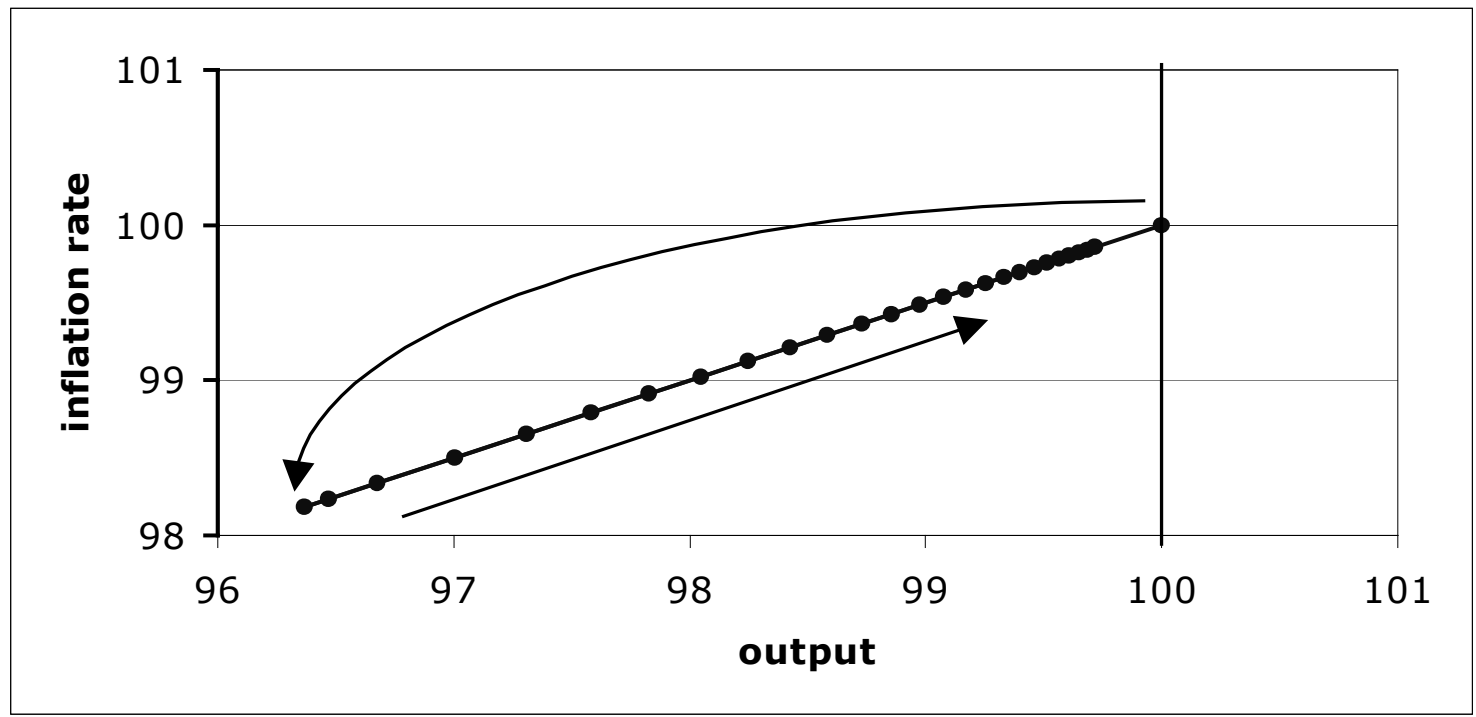

- The shock has transitory effects on output and inflation, owing to the progressive absorption of the interest rate gap, and permanent effects on the nominal interest rate, owing to the fall in the natural rate 
- The system moves to a lower accumulation path, but with no permanent loss of output 16

- On impact, the nominal interest rate lags behind (does not change) vis-à-vis the fall in the NAIRI

- In the next period, output starts falling below potential, with inflation falling below the core level

- The nominal interest rate also starts falling by keeping pace with deflation

- The system converges to a new steady state where output is back to potential, inflation is at the core rate, and the nominal interest rate is reduced to the new NAIRI, given by the lower natural rate plus initial core inflation

- The AS diagram records a positively sloped plot; observations are due to transitory dynamics

B) Temporary nominal shock to the bank interest rate $\left(i_{t}\right.$ falls up to -10 basis points of interest rate gap at time $0 ; r, \pi, y$ held constant $=$ 100)

Figure 3. Time diagram

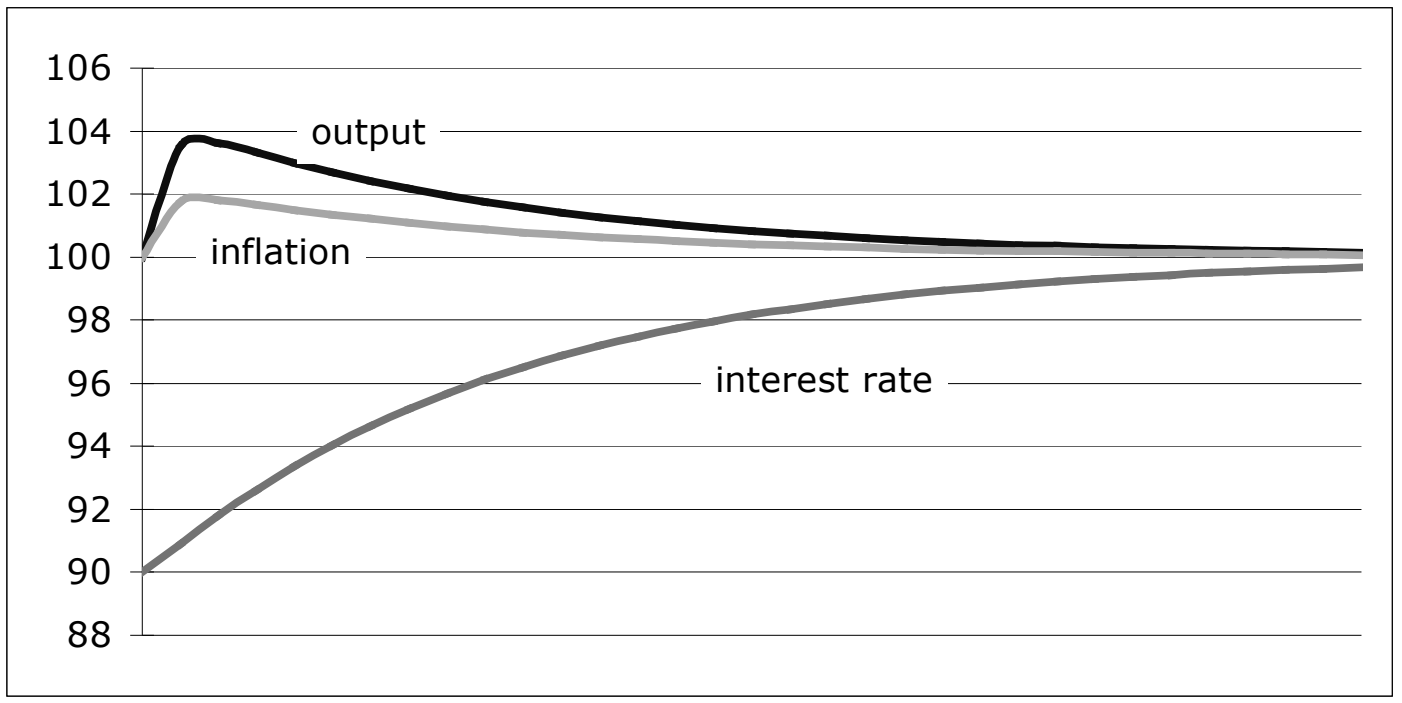

16 A different question is whether along the new accumulation path, the old potential output remains unchanged as assumed in the exercise. The answer depends on how the real wage rate adjusts to the lower natural interest rate. 
Figure 4. AS diagram

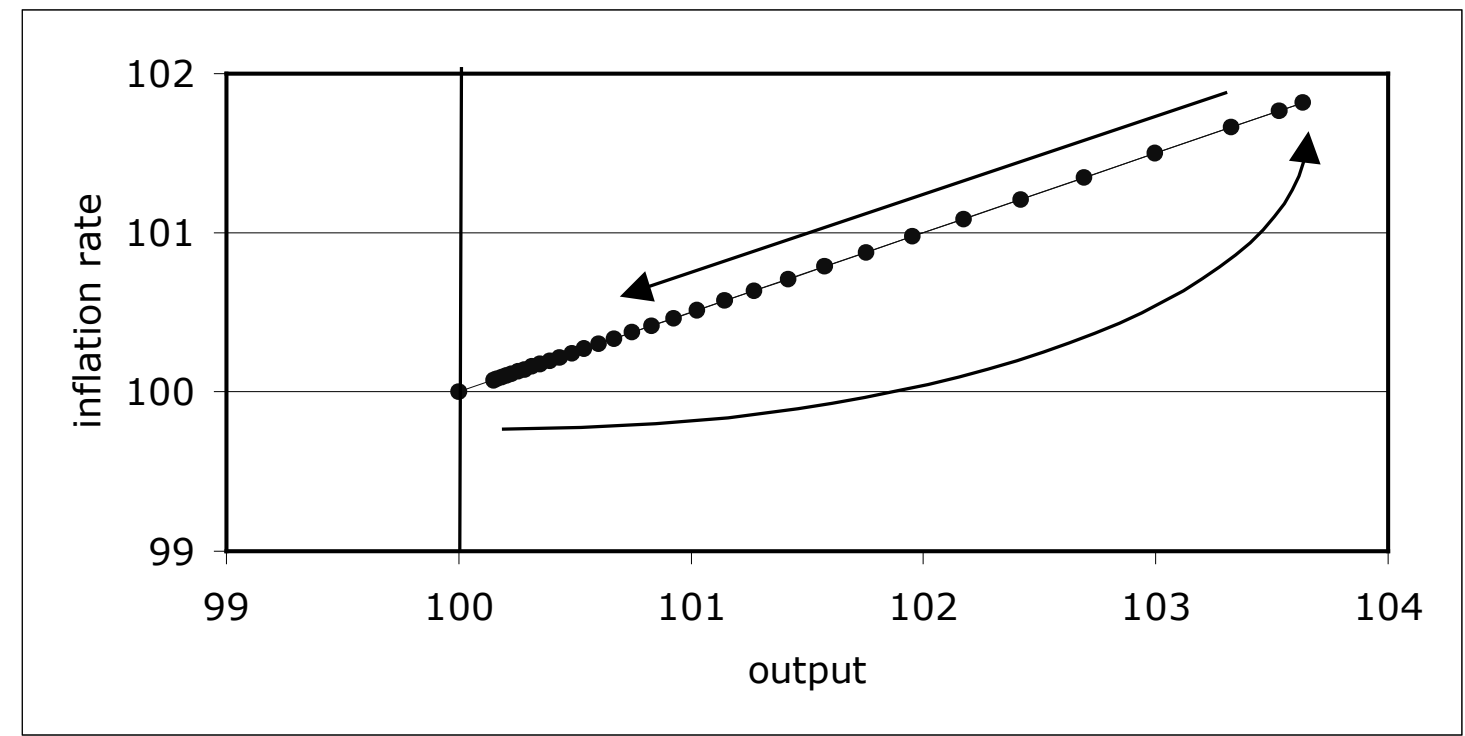

- The shock has only transitory effects on all the real and nominal variables (output and inflation raise), owing to the progressive absorption of interest rate gap

- The AS diagram shows a positively sloped plot; observations are due to transitory dynamics.

To sum up. The Wicksellian bank mechanism exemplifies a class of procyclical market interest-rate processes that progressively absorb the initial interest rate gap, whether this is due to a real or a nominal shock. In each instance examined, the interest-rate adjustment is consistent with the economy's convergence to the steady state and supports a determinate rational-expectations equilibrium. This result hinges on the generalized belief in the core inflation rate $\pi$. To be precise, what the model actually says is that any belief concerning the core inflation rate consistently held by all agents is self-fulfilling. On the other hand, it can be shown (not reported here) that the properties of the system would not survive when this belief is replaced either with "backward-looking" specifications (where e.g. $\pi$ is replaced by $\pi_{t-1}$ ) or with "extrapolative expectations" (where e.g. $\pi$ is replaced by an increasing function in $\pi_{t}$ ). As is well known, Wicksell was aware of, and worried about, the 
indeterminacy of the inflation rate over pure credit cycles. And this is, of course, an important message for monetary policy to which we shall return. Of less importance, instead, is the hypothesis of short-run rational expectations, i.e. condition (3). For instance (not reported here), the system would still converge to the theoretical steady state if, say, entrepreneurs had static expectations (i.e. $\pi_{t+1}^{e}=\pi_{t+1}$ is replaced by $\pi_{t}$ in equation (1)).

A second conclusion concerns the Keynesian issue of "involuntary unemployment" over the cycle. As is clear, the Wicksellian bank mechanism does not lead to excess unemployment (loss of output) in the steady state (only in the transitory dynamics). Hence, explanations of involuntary unemployment as a steady-state phenomenon should look for other mechanisms that prevent the interest rate gap from being closed (see also Leijonhufvud (1981)). The next candidate is of course the Keynesian monetary theory of the interest rate.

\subsection{Dynamic LM}

These exercises have the instructive by-product of making it immediately clear that the standard specification of the LM equation cannot be used to address the problem at hand, which is intrinsically dynamic. Thus the numerous complaints about the "static" nature of the LM and its misfit with genuinely Keynesian economics seem vindicated.

I have thus devised a "dynamic LM" equation for the nominal interest rate in the following way. Let us start from the textbook LM function which represents the interest rate as a function increasing in current real income and decreasing in real money supply 17 . If $\mu_{y}$ and $\mu_{i}$ are the income and interest-rate elasticities of money demand, then $1 / \mu_{i}$ $\equiv \delta$ and $\mu_{y} / \mu_{i}=\mu_{y} \delta$ are the elasticities of the interest rate relative to real

17 The typical LM function is obtained by starting from a log-linear money demand function,

$$
m^{d}{ }_{t}=\mu_{y} y_{t}-\mu_{i} i_{t}
$$

Equating money demand to real money supply, $m_{t}-p_{t}$, the equilibrium interest rate is

$$
i_{t}=\left(\mu_{y} / \mu_{i}\right) y_{t}-\left(1 / \mu_{i}\right)\left(m_{t}-p_{t}\right)
$$


money supply and real income, respectively. This theory implies that the interest rate is constant over time as long as real income and real money supply are constant. Accordingly, a simple dynamic equation consistent with this theory is the following:

$$
i_{t}=i_{t-1}+\mu_{y} \delta\left(y_{t}-y_{t-1}\right)-\delta\left(\hat{m}_{t}-\pi_{t}\right)
$$

where $\hat{m}_{t}$ is the growth rate of money supply.

Also this mechanism has a very limited informational requirement, being entirely based on step-by-step adjustment to current observable variables with no need for public information on the natural interest rate. There are two main differences with respect to the Wicksellian bank mechanism. One is the sensitivity to output dynamics, the other is the dependence on an exogenous dynamic variable - money supply.

Adding equation (10) to system (1)-(3) and rearranging, the steadystate values of the endogenous variables are still $\bar{y}=y, \bar{i}=i, \bar{\pi}=\pi$, provided that $\hat{m}_{t}$ is constant and equal to the core inflation $\pi$. Given $\hat{m}_{t}$ $=\pi$, we now have the following condition for monotonic convergence and stability:

$$
\delta \leq \rho^{\prime} / \alpha^{\prime} \mu_{y}
$$

The economic message is that the properties of the system now crucially hinge on the relationship between the parameters that relate the dynamics of the nominal interest rate to both inflation and output. In particular, stability implies an inverse relationship between the two. On the other hand, the smaller is $\delta$, the smoother is the interest rate dynamics and the longer is the whole adjustment process.

Let us now examine the same previous shocks as in the Wicksellian bank mechanism. The parameter $\mu_{y}$ has been set equal to 0.5 . For the sake of comparison, the value of parameter $\delta$ has been set equal to 0.5 , like the analogous parameter $\gamma$ in the Wicksellian simulation, and in line with condition (11), which in our case is 0.67 . 
A) Permanent real shock to the NAIRI ( $r$ falls up to 10 points of interest rate gap at time 0 and forever (new NAIRI $=90$ ); $\pi, u$, and $\hat{m}$ held constant $=100$ )

Figure 5. Time diagram

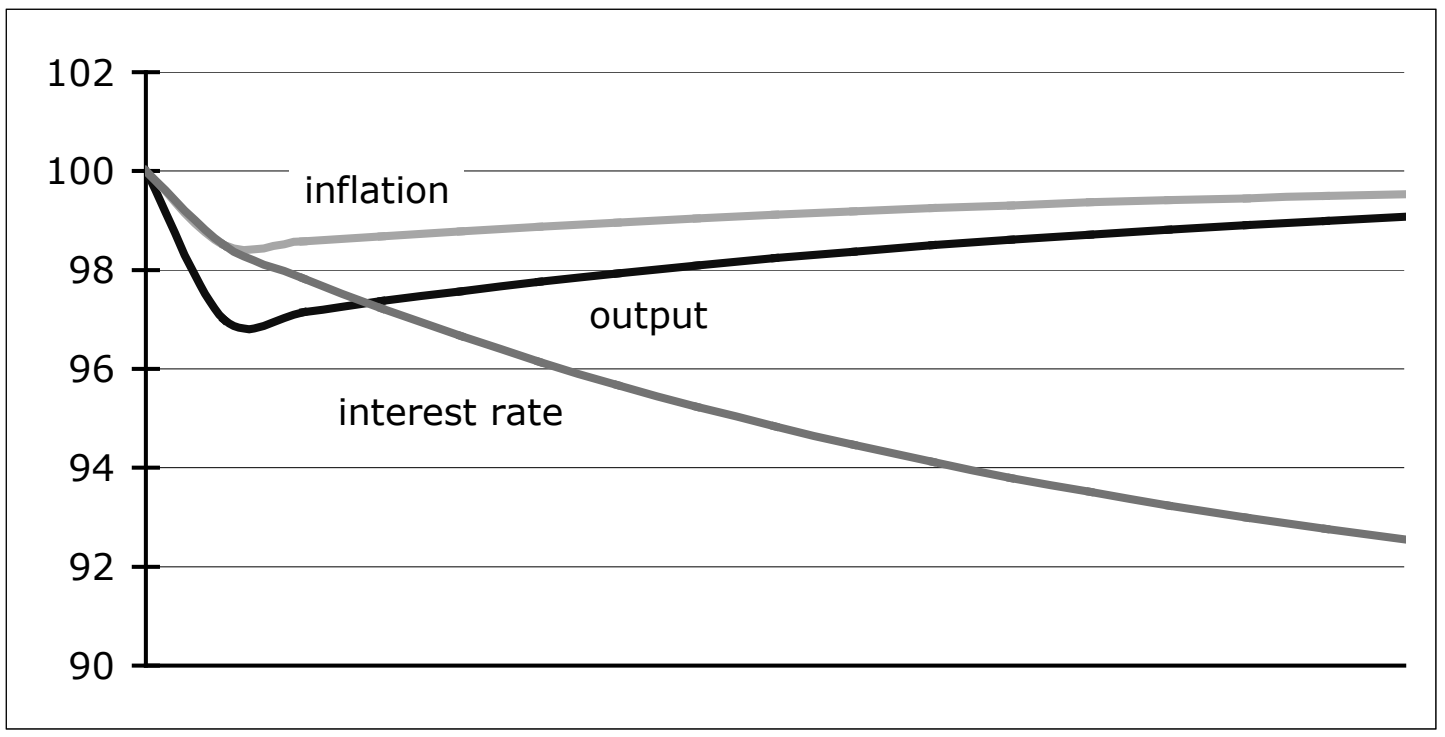

- The shock has the same qualitative effects as in the Wicksellian case. The negative out gap is reabsorbed along with the positive interest rate gap.

- After the positive interest rate gap at time 0 , output falls and deflation is triggered

- The income and real-balance effects work: they progressively reduce the nominal interest rate and close the interest rate gap.

- The AS diagram would display the same plot as the analogous Wicksellian case (see Figure 2) 
B) A temporary monetary shock ( $\hat{m}$ rises up to -10 points of interest rate gap at time $0 ; r, y$ and $\pi$ held constant $=100$ )

\section{Figure 6. Time diagram}

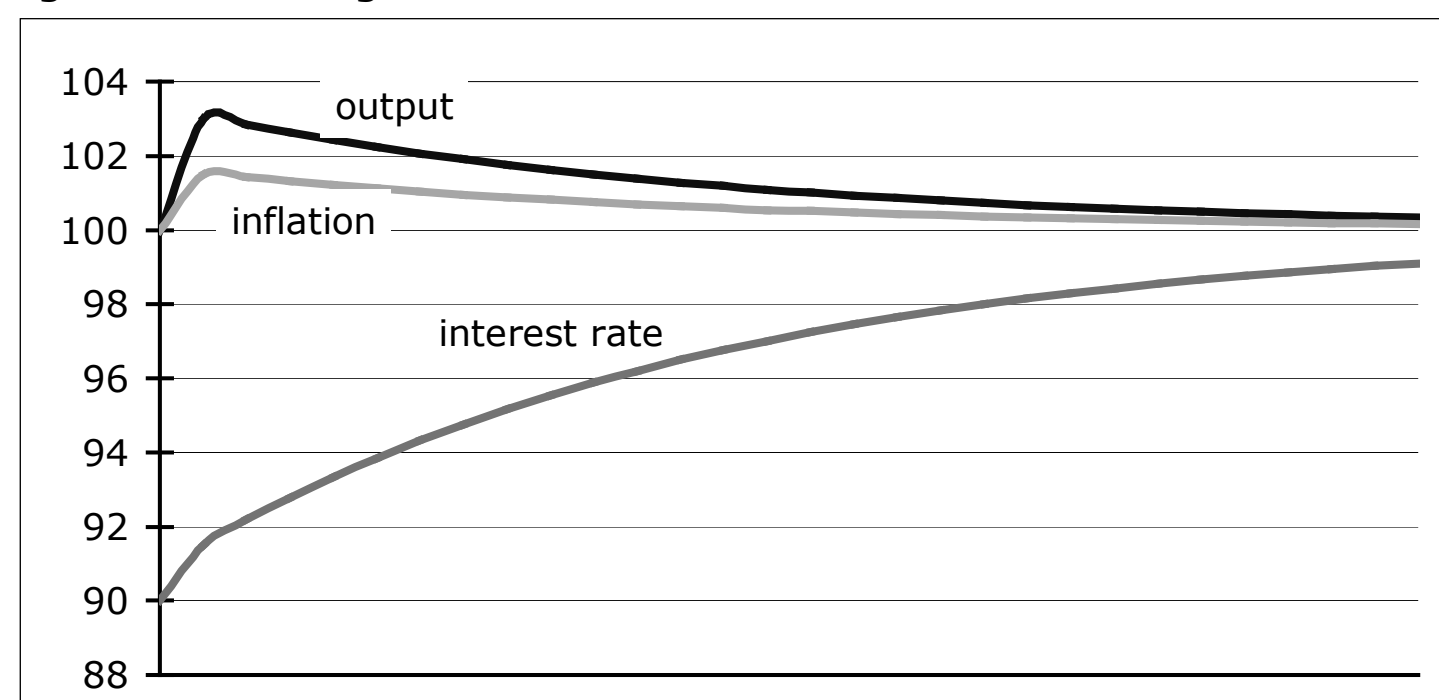

- The shock has transitory effect on all variables

- On impact, the nominal interest rate falls below the NAIRI and boosts output

- Thereafter, the increase in inflation reduces real money balances and drives the interest rate to its initial steady-state value

- The AS diagram would display the same plot as the analogous Wicksellian case (see Figure 4).

The most important lesson to be drawn from this exercise is that even a Keynesian LM interest-rate equation closely reproduces the results of the Wicksellian one. The inclusion of the output sensitivity of the interest rate may only change the speed and path of the dynamics of the endogenous variables unless the relevant parameter is very high, in which case it may destabilize the system.

From the Keynesian (Old Synthesis) point of view, two are the most striking implications - which basically amount to the Monetarist interpretation of the Old Synthesis (see also Leijonhufvud (1981)). The first is that the Keynesian theory of the interest rate does not seem, per se, sufficient to explain a steady state with involuntary unemployment. The economy, as in the Wicksellian view, seems to be endowed with 
reliable self-stabilizing mechanisms (in particular the real balance effect on money demand) in the cases of both real and nominal business cycles. The second implication is that, apart from accelerating and smoothing the adjustment process, little scope is left for monetary policy. Its most important role is instead more Friedmanite than Keynesian. As stressed in the discussion of the Wicksellian case, the self-stabilizing property of this economy still relies on the agents' common belief in the core inflation rate $\pi$, which is in fact realized in the steady state. In this case, however, this belief is not arbitrary but can (or should) be anchored to a given state variable, namely the money growth rate. In fact, the model shows that the steady-state inflation rate is always equal to the money growth rate, and hence this provides the only rational belief about the core inflation ${ }^{18}$.

Of course, it may be argued that the model assumes a notoriously critical non-Keynesian feature, namely rational expectations of the entire path of inflation as implied by the Phillips and the inflation expectation equations (2) and (3). Yet it can be shown (not reported here) that replacing these equations with backward-looking versions (with $\pi_{t}$ instead of $\pi$ in (2) and instead of $\pi_{t+1}$ in (3)) does not change the qualitative results of the model as long as the NAIRI is computed at the "right" steady-state value given by $r+\pi, \pi=\hat{m}$.

\subsection{Speculative LM.}

The last alternative determination of the nominal interest rate to be examined follows from the last sentence in the previous paragraph, and draws on one among the many criticisms raised against the textbook LM version of Keynes's theory of the interest rate. The thrust of this criticism is that one major element in that theory, the "speculative motive" of the demand for money, has gone completely astray (Leijonhufvud (1981)). A truly "speculative" component of money demand should be related to expected movements of the interest rate relative to its future value, say $i^{s}$. Speculators substitute bonds for money whenever

18 The reason is that the adjustment process of $i_{t}$ ceases only when $\pi_{t}=\hat{m}$ 
they expect capital gains, i.e. a rise in the bonds price or else a fall in the market interest rate. Therefore, this component should enter the usual representation of money demand as a negative function of $\left(i_{t}-i^{s}\right)$ (Leijonhufvud (1981), p.146). The dynamic LM should therefore be rewritten as follows

$$
i_{t}=i^{s}+\mu_{y} \delta\left(y_{t}-y_{t-1}\right)-\delta\left(\hat{m}_{t}-\pi_{t}\right)
$$

This specification implies that as long as real income and real money supply are constant, speculation keeps the market interest rate aligned with $i^{s} .19$

Now this determination of the nominal interest rate has a crucial informational requirement, that is, $i^{s}$. It is clear that the marginal firm in the bonds market can be expected to pay in real terms no more and no less than $r$ to investors; hence the benchmark rate for rational speculators should be the NAIRI. In other words, rational speculators should have the same inside information as firms about the natural interest rate. I have simulated two situations vis-à-vis a permanent change in the natural rate, one where speculators have this information and one where they do not. The parameters are the same as in the previous LM model.

19 Since in equation (12) the fixed exogenous term $i^{s}$ replaces the lagged value of the nominal interest rate $i_{t-1}$, the convergence and stability conditions are now slightly different than in the plain LM case. In particular, as can been seen from the simulation below, the same values of the parameters now yield oscillatory convergence. 
A) A permanent real shock to the NAIRI: full information ( $r$ falls up to 10 basis points of interest rate gap at time 0 and forever (NAIRI = 90); $i^{s}=$ NAIRI at time 1 and forever; $\pi, y$, and $\hat{m}$ held constant $=100$ ).

\section{Figure 7. Time diagram}

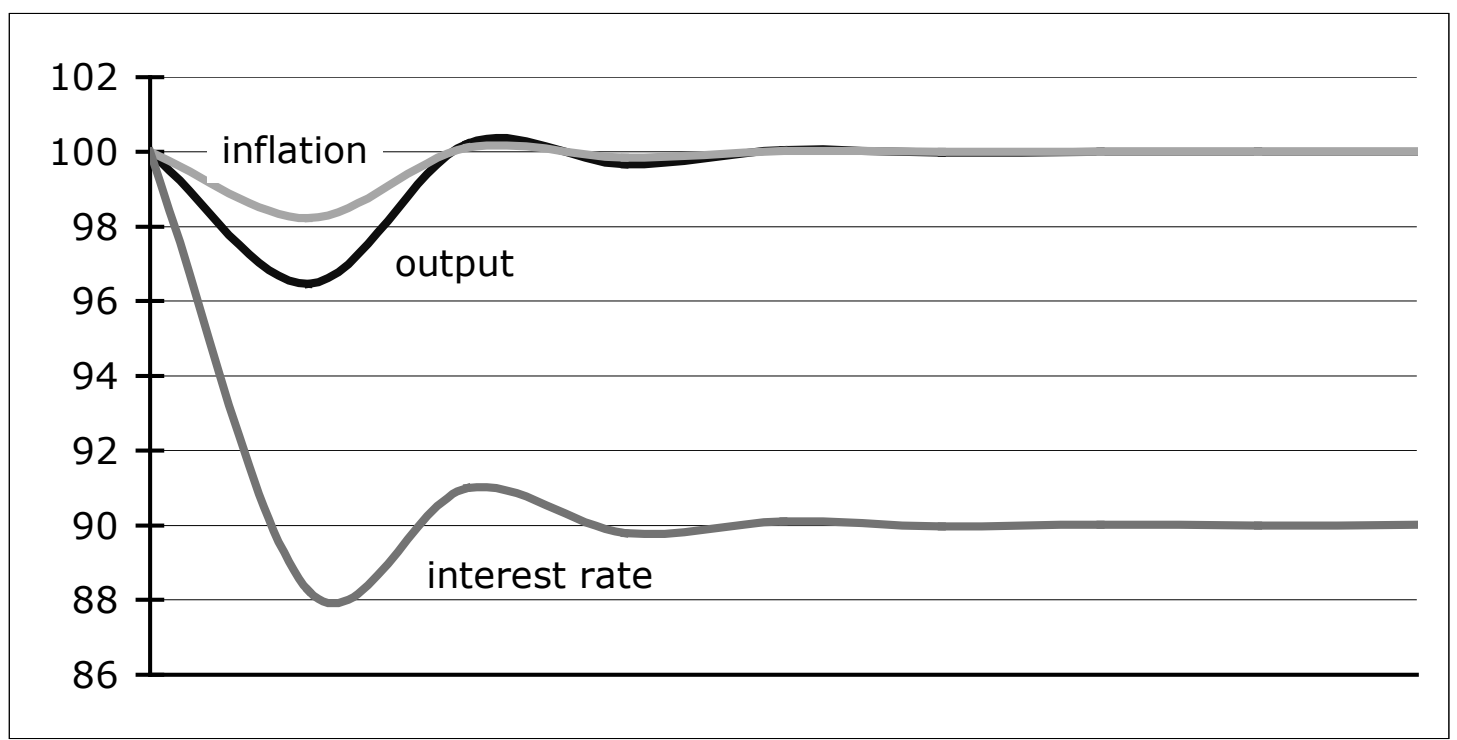

- The shock has the same qualitative effect as the plain dynamic LM.

- The initial impact on the interest rate is larger since it embodies the lower NAIRI, which is however overshot owing to the concurrent reduction in money demand exerted by lower output and lower inflation

- Initial overshooting of the market interest rate generates oscillatory dynamics. 
B) A permanent real shock to the NAIRI: limited information $(r$ falls up to 10 basis points of interest rate gap at time 0 and forever (new NAIRI $=90) ; i^{s}, \pi, u$, and $\hat{m}$ held constant $=100$ ).

Figure 8. Time diagram

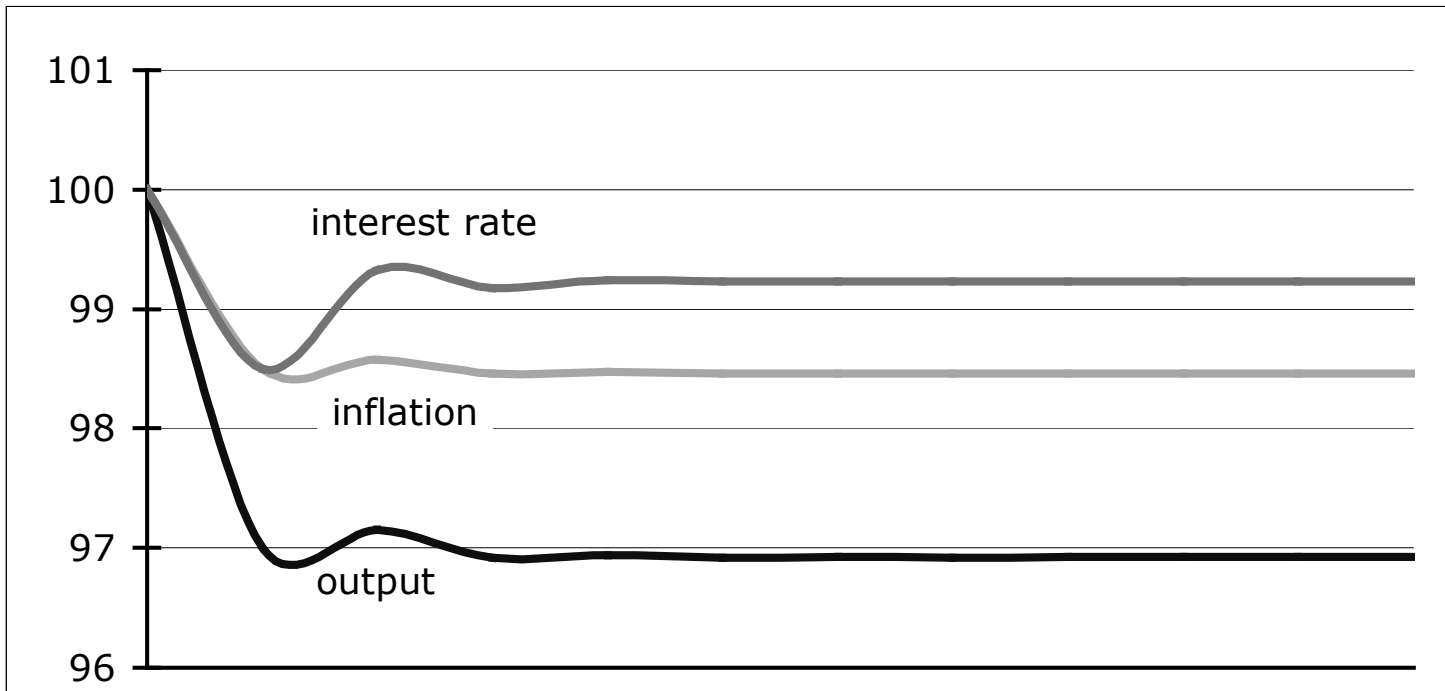

Figure 9. AS diagram

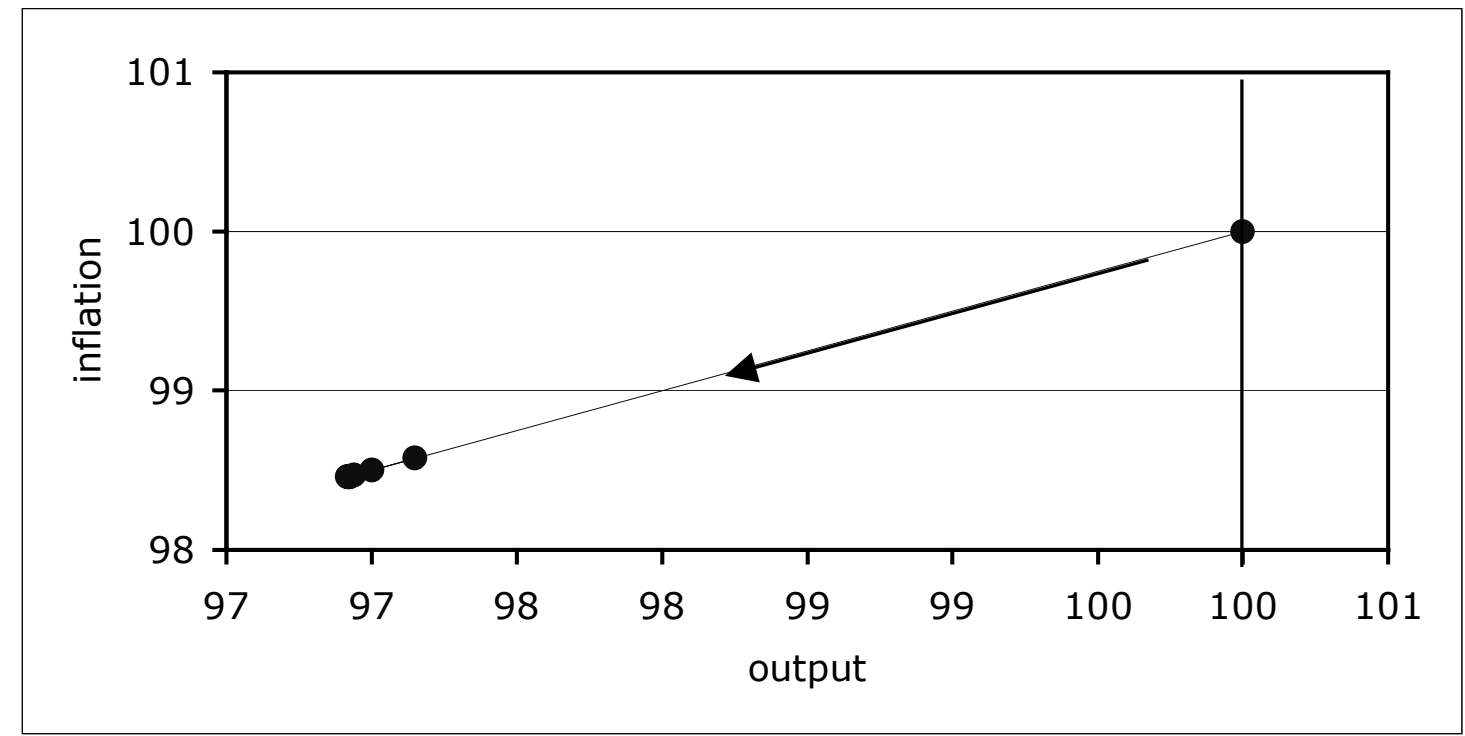


- The shock has permanent effects on both real and nominal variables. In the steady state, output is below the potential level, the nominal interest rate is above the NAIRI, and inflation is below the core rate.

- The AS diagram shows a positively sloped schedule and observations are due to transitory dynamics towards a lower steady state

This scenario seems to have genuine Keynesian features, in that "involuntary unemployment" (permanent negative output gap) emerges because the speculative demand for money prevents the market interest rate from falling enough to offset the fall in the natural rate. The fundamental cause is that speculators do not adjust their benchmark rate to the lower NAIRI. There are however several problems hidden behind this result:

- the exercise has been run holding the core inflation rate $\pi$ constant at 100: yet this expectation turns out to be wrong, because the steady state inflation will be lower (thus the new steady-state NAIRI is even lower than after the initial shock since both $r$ and $\pi$ have fallen)

- in the new steady state the inflation rate is lower than the money growth rate (held constant at 100); hence real money balances keep on growing and create excess purchasing power in the hands of speculators

- on the other hand, the market interest rate stabilizes at a value lower than $i^{s}=100$ expected by speculators, who should therefore keep on anticipating capital losses in the bonds market, which prevent them from buying bonds.

It therefore seems that the steadiness of the wrong nominal interest rate is due not to the absence of forces of change but to two countervailing out-of-equilibrium wrong forces 20 . Being fraught with

20 It is tempting to see here a possibile manifestation of the liquidity trap (clearly any further increase in the money growth rate would be useless). If this is the case, it seems necessary to conclude that the liquidity trap cannot be regarded as an extreme case in the Keynesian pathology but is indeed the Keynesian pathology! Are therefore Pigou and Modigliani vindicated? Not exactly. A methodological point in the "Wicksell Connection" applies here, namely that the pathological states of the system are not due to structural 
expectational errors, however, this scenario can hardly be considered a genuine steady state. This finding probably frustrates the Keynesians' search for "involuntary unemployment equilibria"; but on the other hand, it is also challenging in that it points out at least one case in which, in a well-specified sense, a purely market-driven interest rate may put the system on the wrong track. Moreover, it is difficult to see where the system can be driven from here, since the corrections of the underlying errors may prove far from smooth and painless.

\section{Monetary policy}

The previous conclusions prompt thoughts on monetary policy as a visible hand possibly keeping the interest rate on the right track. I have considered the most popular policy rule on the menu of modern central banks: the Taylor rule. Interestingly, we shall see that it can be regarded as a combination of the Wicksellian and the Keynesian interest-rate models examined above.

The Taylor rule has a variety of specifications which can be summarized as follows:

$$
i_{t}=i^{*}+\varphi\left(y_{t}-y\right)+\theta(\tilde{\pi}-\pi)
$$

where $i^{*}$ is the benchmark nominal rate, and $\tilde{\pi}_{t}$ is the informational inflation rate (the inflation rate used to assess the cyclical position of the economy).

In empirical versions, the benchmark rate $i *$ is often replaced by the so-called "interest-smoothing" mechanism, i.e. a gradual adjustment of the interest rate from the previous period, and current inflation is used as informational input. Thus, if we set $i^{*}=i_{t-1}$ and $\tilde{\pi}=\pi_{t}$ we obtain an "adaptive Taylor rule". In the more theoretically-oriented versions, usually based on some optimization exercise, $i *$ is nothing other than our

parameters but to particular combinations of events and the way in which they are processed by markets. In fact, the pathology we have found is not due to anomalous liquidity preference (the parameter $\lambda$ is always the same) but to an informational/expectational error. The implications concerning the relevance of the problem are quite different. 
NAIRI and $\tilde{\pi}_{t}$ is the forecast of the inflation rate (in the absence of policy interventions). The result is often presented as (forecast) inflation targeting corrected for output smoothing. Substituting $i$ and $\pi_{t+1}^{e} \mid i_{t-1}$ into equation (13), we obtain a "forward-looking Taylore rule". Let us examine the two specifications in turn.

\subsection{Adaptive Taylor rules}

As explained above, an instance of this class of rules is the following:

$$
i_{t}=i_{t-1}+\varphi\left(y_{t}-y\right)+\theta\left(\pi_{t}-\pi\right)
$$

It is immediately evident that this interest-rate mechanism nests the Wicksellian one (if $\varphi=0$, see equation (8)). In short, this respecification highlights the key role of the central bank as an "expectations manager" advocated by Wicksell (see also Woodford (2003), ch. 1). Here, the anchor of expected inflation is explicitly set by the central bank, and is given by the target $\pi$ itself. On the other hand, it is also clear that (14) is merely a variation of our plain dynamic LM (10), once the money growth rate has been replaced by the target inflation rate. In essence, this reflects the shift from the Friedmanite view of monetary policy conduct (based on the control of the money growth rate, with the nominal interest rate as an endogenous variable) to the NNS view (based on the control of the nominal interest rate, with the money growth rate as the endogenous variable). Nonetheless, the structural framework is analogous: that is a dynamic LM-type equation 21 .

21 For inexplicable reasons, the belief is growing that the straigthforward use of the Taylor rule instead of the discredited LM equation in standard AD-AS macroeconomic models is a major change and improvement, especially for teaching purposes (e.g. Taylor (2000), Carlin and Soskice (2004)). I think that my treatment highlights the analogy between a properly dynamized LM and the Taylor rule. From the policy point of vew, the only "deep" difference between the two is the usual one between the quantity of money and the interest rate as instrument. An LM equation like (10) indicates how the central bank should gear the money growth rate in order to control the capital market interest rate. The Taylor rule indicates the desired interest rate and assumes as a short-cut that the central bank can set this rate directly at will. In a more refined framework, the dynamic LM and the Taylor rule can only be complementary, since it is hard to see how the central bank can control anything if it is not 
Equation (14) implies that the steady-state solution of the whole system, $\bar{y}=y, \bar{i}=i, \bar{\pi}=\pi$, exists. As to monotonic convergence and stability, some qualifications drawn from the LM case are in order. The first is that the output and inflation gaps parameters cannot be chosen independently. Instead, they should satisfy a structural relationship dictated by the system's stability, which in the case of the adaptive Taylor rule is

$$
0<(\varphi+\theta \beta)<\frac{1+\rho^{\prime}-2 \rho^{1 / 2}}{\alpha^{\prime}}
$$

Once this condition is satisfied, the specific advantage of targeting $y$ and $\pi$ explicitly in the interest-rate equation is that convergence is faster and smoother than in the Wicksellian and LM processes. If the central bank does have full information about the (optimal) targets, this result may provide a rationale for direct interest-rate control by the central bank.

Note that $(\varphi+\theta \beta)$ is the compound response of the nominal interest rate to 1 point of output gap, both directly $(\varphi)$ and indirectly via inflation gap $(\theta \beta)$. The Taylor-rules literature seems unaware that the two gaps that feed the interest-rate adjustments are, in general, correlated in relation to the type of shock that hits the economy and the subsequent dynamic process. From this point of view, the standard Taylor rule looks like a quasi-reduced form of a structural form that includes a relationship between inflation and output gaps ${ }^{22}$. Our system (1)-(3) is a case in point. Clearly, equation (2) can be used to replace

consistent with money demand and supply (flow) equilibrium. In fact, the true instrument that the central bank can control directly is the discount rate, which is in its turn a means to regulate credit creation and hence the money growth rate. If the Taylor rule, as in its empirical applications, is taken to represent how the central bank wishes to manage the discount rate, then assuming a stable relationship between the discount and money growth, the dynamic LM equation yields the changes in the interest rate consistent with the equilibrium of money demand and supply.

22 This remark can be traced back to a basic and yet unresolved question: where does the Taylor rule come from? It is true that some authors have proved that it can be derived from standard policy optimization. Nonetheless, the rationale of a policy rule which apparently treats correlated variables as independent is far from clear. 
either the output or the inflation gap in equation (14), so that only one of the two remains. Consider the cases in which the two gaps are positively correlated: then the mechanical application of the Taylor rule would imply that the interest rate reacts twice to the same signal. Hence condition (15) highlights that the system's stability requires that this compound response be limited upwards.

From this point of view, the scope for the choice of the two policy parameters is constrained by the system's stability requirement. From condition (15) we see that, along the stability frontier, if one wants to raise the sensitivity to inflation gaps $\theta$, the sensitivity to output gaps $\varphi$ should be reduced, and vice versa. Note, also, that the more prices are flexible ( $\beta$ is large), the smaller $\theta$ should be. This may seem somewhat paradoxical, but it is perfectly consistent from the mathematical point of view. In an economy with fully flexible prices, the bulk of adjustments to interest-rate gaps would take place through changes in the inflation rate. Large fluctuations in the price level were in fact at the root of Wicksell's concerns. On the one hand, high aversion to price instability would generate overreaction to inflation gaps; on the other, the system's stability indicates that, when prices are flexible, small changes in the interest rate are sufficient.

A further implication is that the so-called "Taylor principle", that is the requirement that the inflation-gap parameter $\theta$ be greater than 1 (Woodford (2001)), is neither necessary nor sufficient. For particular combinations of very low persistence $\left(\rho^{\prime}\right)$ and/or very high elasticity $\left(\alpha^{\prime}\right)$ of output gaps with respect to interest-rate gaps, $\theta>1$ might even turn out to be destabilizing. On the other hand, once the relevant stability condition is verified, $\theta<1$ may well be sufficient.

Let us now look at a simulation where the Taylor-rules parameters are set to $\varphi=0.5, \theta=0.5$. These values enable comparison with the previous cases. Note that the limit value for $\theta$ is 1.45 (incidentally $\varphi=0.5$ and $\theta=1.5$ were the values originally estimated by Taylor (1993) for the United States). 
A) Permanent real shock to the NAIRI ( $r$ falls up to 10 points of interest rate gap at time 0 and forever (new NAIRI $=90$ ); $\pi$, and $y$ held constant $=100$ )

Figure 10. Time diagram

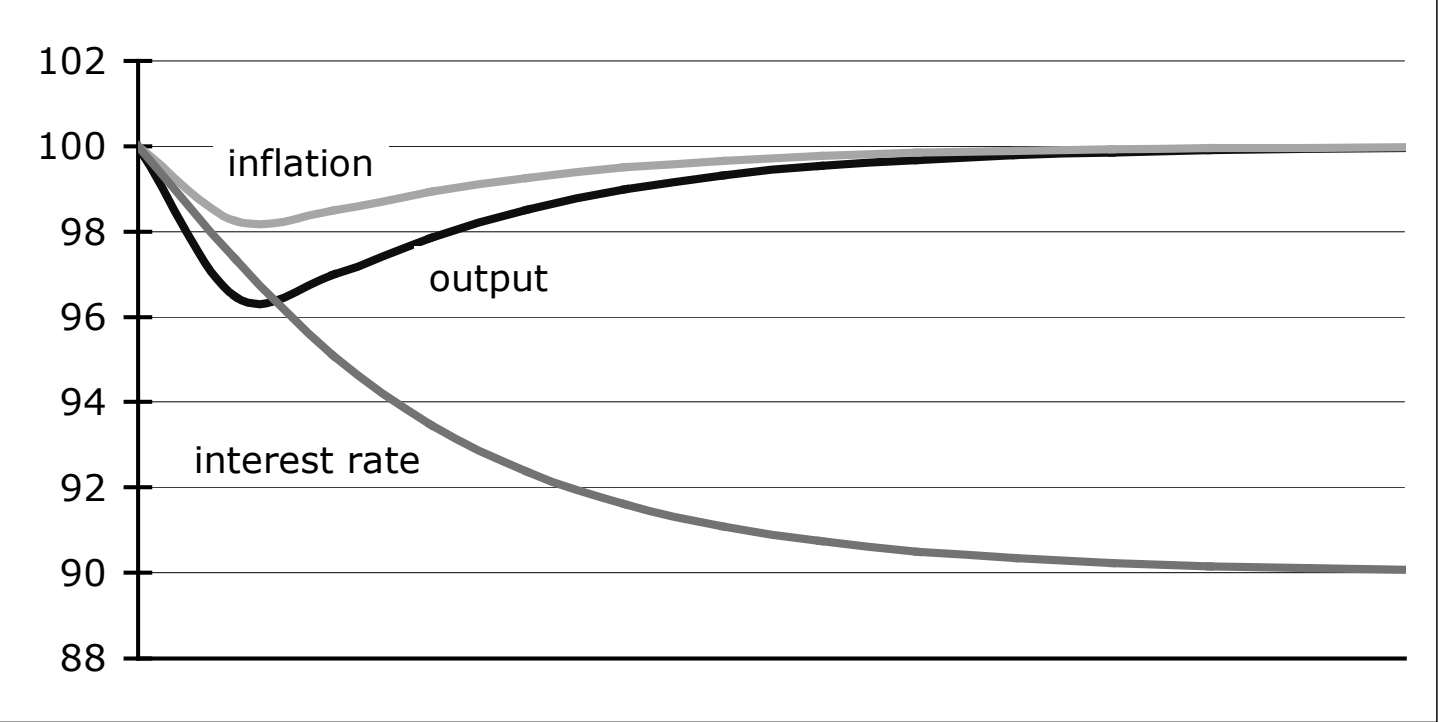

- The adaptive Taylor rule is sufficient to correct for a permanent real shock to the NAIRI with no permanent effect on output and inflation.

- Convergence displays the same qualitative properties as the market driven processes (the Wicksellian and the Keynesian), though it is faster and smoother (this is due to the compound effect of comovements in the inflation and output gaps on the interest rate) Of course, shocks to the interest-rate gap are not the sole concern of central banks. Given the particular interest of supply-side shocks for monetary policy, let us examine how the adaptive Taylor rule performs in this case. 
B) Permanent real shock to potential output ( $y$ falls up to 10 points at time 0 and forever; $\pi$ and $i$ held constant $=100$ )

\section{Figure 11. Time diagram}

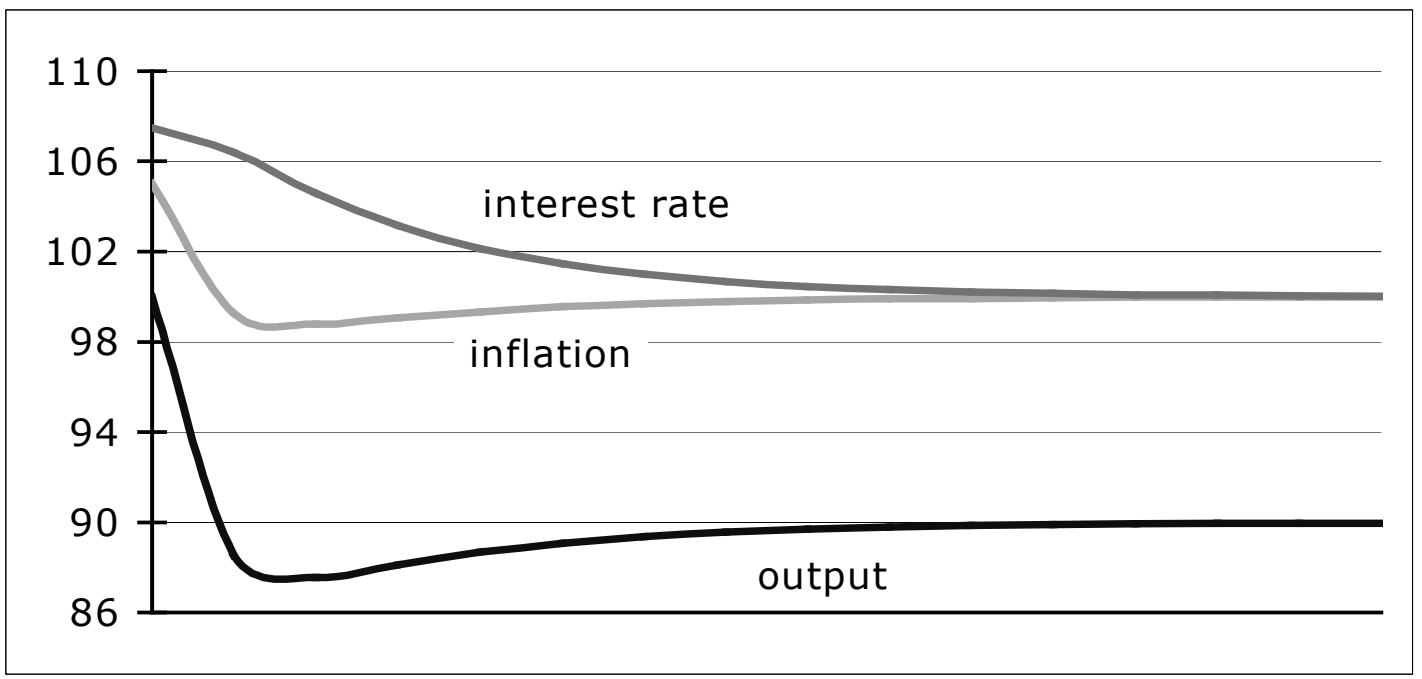

- The shock triggers a stagflationary process. The adaptive Taylor rule is consistent with the system's converging to a new steady state with lower potential output, and unchanged inflation and natural interest rate

- A noteworthy feature of this process is output overshooting. The magnitude of the sensitivity to inflation gaps $\theta$ determines the first response of the interest rate to the initial inflation spike. To the extent that the interest rate is immediately raised, the inflation gap is damped, whereas output overshoots with respect to the new steady state value.

- The inflation-output trade-off embedded in the policy rule concerns, not the steady-state values, but the variability trade-off of output and inflation (Taylor and Solow (1998)).

\subsection{Optimizing Taylor rules}

Specific consideration should be made of the Neo-Wicksellian prescription that the Taylor rule should be pegged to the natural rate of interest (Woodford (2003)), that is, $i^{*}=i$ in our formulation. Another theoretically-oriented sophistication of the Taylor rule consists in the socalled "forecast targeting" (Svensson (1997)). This is a specification 
where the inflation gap is measured with reference, not to the current inflation rate, but to its forecast (in the absence of policy intervention). The formulation of a forward-looking Taylor rule is therefore,

$$
i_{t}=i+\varphi\left(y_{t}-y\right)+\theta\left(\pi_{t+1}^{e} \mid i_{t-1}-\pi\right)
$$

Generally, these reformulations of the Taylor rule are also grafted onto an explicit optimal-control problem of the central bank (see e.g. Clarida et al. (1999), Woodford (2003), ch. 8). This is in fact also the case with our model, where equation (16) can obtained from the following optimal-control problem ${ }^{23}$

$$
\begin{aligned}
& \left.\max L_{t}=-\sum_{t}^{\infty} \frac{1}{2}\left[\left(y_{t}-y\right)_{t}^{2}+\sigma\left(\pi_{t}-\pi\right)_{t}^{2}\right)\right] \\
& \text { s.t. }\left(\pi_{t}-\pi\right)=\beta\left(y_{t}-y\right)
\end{aligned}
$$

where $\sigma$ measures the degree of inflation (variability) aversion. The most important implication of optimization is that the parameters of the Taylor rule are no longer arbitrary, but are determined by the structural parameters of the model, i.e.

$$
\varphi=\rho^{\prime} / \alpha^{\prime}, \quad \theta=\sigma \beta / \alpha^{\prime}
$$

Whereas a generic specification like (16) produces no major qualitative differences with respect to the adaptive one concerning existence and convergence towards the steady state, the specification with the optimizing parameters has the noteworthy consequence that, for any $\sigma>0$, the system loses monotonic convergence. The system retains stability provided that

$$
\sigma<\frac{1}{\left(1+2 \rho^{\prime}\right) \beta^{2}}
$$

Once again, the degree of inflation aversion of the central banker cannot be merely a matter of taste, but should be consistent with the requirement of system stability.

Some features of the adjustment process can be appreciated by looking at the simulation of our usual shock, where $\sigma=1.5$ (i.e. inflation variability weighs $50 \%$ more than output variability) and the maximum

23 See Appendix A.3. 
value of $\sigma$ for stability is 3.2. Note that $\sigma=1.5$ generates $\theta=2.1$ in the Taylor rule, which is in fact a relatively large value.

A) Permanent real shock to the NAIRI ( $r$ falls up to 10 points of interest rate gap at time 0 and forever (new NAIRI $=90$ ); $\pi$, and $y$ held constant $=100$ )

Figure 12. Time diagram

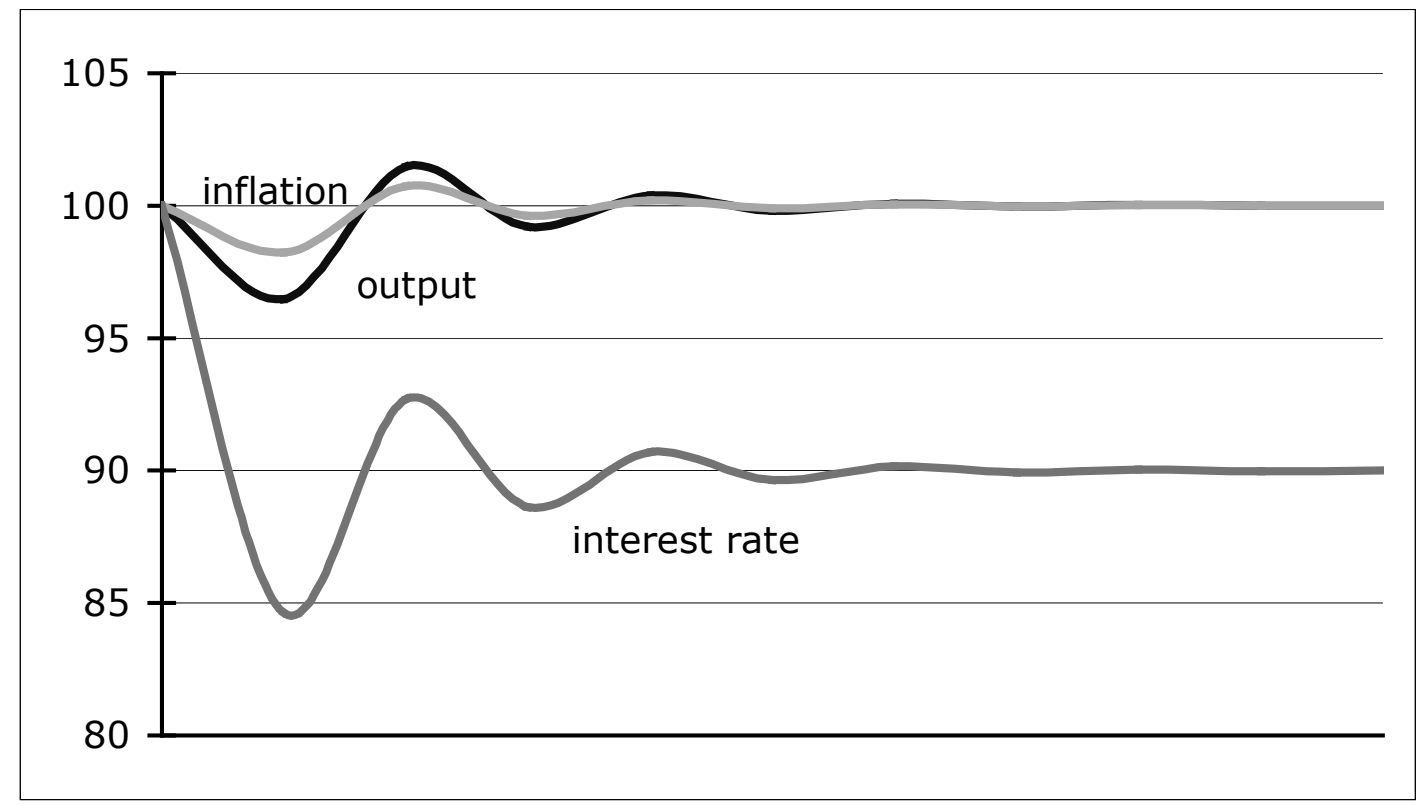

As explained above, the optimizing, forward-looking components of the Taylor rule accelerate the adjustment process, but they also introduce oscillations. In other words, an optimizing, forward-looking Taylor rule requires more stringent conditions on the magnitude of the parameters in order to ensure monotonic convergence.

A second important observation is that a Taylor rule pegged to the NAIRI is analogous to our speculative LM function, when speculators know the right NAIRI, with the exogenous money growth rate $\hat{m}$ replaced by the target inflation rate $\pi$. In fact, $\hat{m}$ and $\pi$ play the same role indicating what the core inflation should be for the central bank. Indeed, the same conclusion applies: namely, that targeting the NAIRI directly may be dangerous when it is not known with certainty. In a recent study published by the ECB, one reads that 
from the empirical point of view, the "natural" real interest rate is unobservable. The estimation of the natural real interest rate is not straightforward and is associated with a very high degree of uncertainty (Garnier and Wihelmsen (2005), p.6).

If the central bank has complete and immediate information about the NAIRI, then it can and should immediately adjust the nominal interest rate to offset any change in the NAIRI as it arises (in our simulation, the new NAIRI is introduced in the rule one period later). If the central bank does not have this information, and it happens to peg the nominal interest rate to the wrong NAIRI, then the Taylor rule would drive the system towards a permanent output gap, like the speculative LM function with limited information.

\section{Conclusions}

Let me summarize the main findings of this exploration of the Wicksellian lessons for modern macroeconomics and monetary policy conduct.

First, the main distinction of the original Wicksellian theory with respect to the DSGE framework of the NNS can be seen in the focus on disequilibrium business cycles. This type of cycles are driven by "interest rate gaps" between the market interest rate and the NAIRI and by saving-investment imbalances. Nominal wage-price stickiness is not the only problem, wage-price flexibility is not the only solution (in fact, Wicksell's concern with this type of cycles was not related to any role of wage-price stickiness).

Second, these cycles are benign as long as the system has a "nominal anchor" (a given core inflation rate in which agents have reason to believe), and the market interest rate is driven to close the gaps with the NAIRI. These conditions are probably more robust than Keynesians (and Keynes?) believe(d), and the mere existence of the interest elasticity of money demand is not an impediment. Nonetheless, this class of cycles remains relevant to the extent that interest rate gaps are frequent, substantial and persistent; even when long-run dynamics is 
benign, frequency, amplitude and persistence of these cycles may make them problematic enough in the short to medium run. A minimal list of requirements for relevance (and concern) is that the NAIRI should be volatile and that it should not be easily transmitted to the capital market; since the NAIRI consists of the natural rate and core inflation, these requirements should apply to both components, or at least to one.

Looking at monetary policy, two main conclusions can be drawn. First, providing the economy with the nominal anchor of expectations mentioned above emerges as the central bank's key task. On the other hand, in this setup the real normative content of the central bank's rulebased behaviour is no longer clear. More in particular, the simulations show that:

- the critical elements that eventually determine whether a rule is good or bad are not parameters but two crucial pieces of information, the NAIRU and the NAIRI: no rule produces good results if the central bank is misinformed about these variables

- if informational problems with a volatile NAIRI are the crux, interestrate mechanisms relying upon timely and precise knowledge of the NAIRI are inapplicable in that they simply rule the problem away; simulations have also shown that these mechanisms are destabilizing if they embody the wrong NAIRI

- thus, unless we can be highly confident that central banks are better (perfectly) informed than the market about the natural rate of interest, "adaptive" rules, using step-by-step adjustments of the interest rate vis-à-vis observable conditions in the economy are preferable in that they produce adjustment paths which are generally slower, but safer

- more generally, the more detailed and information-laden is the rule, the broader the scope of cases in which a change in the reaction function would be beneficial, and the greater the damage that the rule can produce if the information requirements are not met; the oft-heard recommendation that central banks adopt and declare reaction functions with stable parameters is far-fetched 
- the choice of parameters also needs careful scrutiny: the emphasis placed by current analyses on optimizing Taylor rules in the DSGE framework may overlook the requirements of (possibly monotonic) convergence and stability in the course of out-of-equilibrium dynamics.

What now remains of the dramatic distinction between "rules" and "discretion" is an open (perhaps semantic) question.

Further "complications" that may arise from other perspectives are the following:

- In developed countries with relatively stable and predictable inflation, the principal source of potential trouble remains the natural interest rate; and in this respect asymmetric information, heterogeneity of firms, and other capital market imperfections may have a role to play ${ }^{24}$. A somewhat more radical perspective would add behavioural finance as a repertoire of causes for the mispricing of firms' investments.

- New Keynesians à la Greenwald and Stiglitz (1993) would also add that potential output (the NAIRU) is not independent of the level of the NAIRI; or better, they would add that it is co-determined by capital market imperfections that keep the natural rate of interest too high or the funding of firms too low.

- Neo-Hicksians (e.g. Amendola and Gaffard (1998)) stress that "technological shocks" (possibly underlying the volatility of the NAIRI) are as such non existent (e.g. they remain ideas in the mind of entrepreneurs) until they are "validated" by financial means; in this perspective, changes in the NAIRI are not independent of monetary policy and the market interest rate.

24 Are Neo-Ricardian problems with the MEC completely out of play? 


\section{References}

Amendola, M., Gaffard J.L. (1998), Out of Equilibrium, Oxford, Clarendon Press.

Blinder A. (1998), Central Banking in Theory and Practice, Cambridge Mass., MIT Press.

Blanchard O. J. (2000), "What Do We Know about Macroeconomics that Fisher and Wicksell Did Not Know?", Quarterly Journal of Economics, 115, pp.1375-1409.

Boianovsky M., Trautwein M. (2004), "Wicksell after Woodford", paper presented at the History of Economics Society meeting, Toronto, June.

Carlin W., Soskice D. (2004), "The 3-Equation New Keynesian Model: A Graphical Exposition”, CEPR Discussion Paper Series, n. 4588.

Clarida R., Galì J., Gertler M. (1999), "The Science of Monetary Policy: A New Keynesian Perspective", Journal of Economic Literature, 37, pp.1661-1707,

Dixon H. (1995), "Of coconuts, decomposition and a jackass: the genealogy of the natural rate", in Cross $\mathrm{R}$. (ed.), The natural rate of unemployment, Cambridge, Cambrdige University Press.

Evans G. W., Honkapohja S. (2001), Learning and Expectations in Macroeconomics, Princeton, Princeton University Press.

Friedman M. (1969), "The Role of Monetary Policy", American Economic Review.

Garnier J., Wihelmsen B. (2005), "The Natural Real Interest and the Output Gap in the Euro Area. A Joint Estimation", European Central Bank, Working Paper Series, no.546.

Goodhart C. A. (2004), "Review of Interest and Prices by M. Woodford", Journal of Economics, 82, pp.195-200.

Greenwald, B.C., Stiglitz, J.E. (1993), "New and Old Keynesians", Journal of Economic Perspectives, 7, pp.23-44.

Hahn F. H. (1977), "Keynesian Economics and General Equilibrium Theory: Reflections on Some Current Debates", in Harcourt G. C. (ed.), The Microeconomic Foundations of Macroeconomics, London, Macmillan.

Hahn F. H., Solow R. (1995), A Critical Essay on Modern Macroeconomic Theory, Cambridge Mass., MIT Press.

Laidler D. W. (2004), "Woodford and Wiksell on Interest and Prices. The Place of the Pure Credit Economy in the Theory of Monetary Policy", paper presented at the History of Economics Society meeting, Toronto, June. 
Leijonhufvud A. (1981), "The Wicksell Connection. Variations on a Theme", Information and Coordination: Essays in Macroeconomic Theory, New York, Oxford University Press.

Minsky H. P. (1975), John Maynard Keynes, New York, Basic Books.

Moore B. (1988), Horizontalists and Verticalists, Cambridge, Cambridge University Press.

Svensson L. (1997), "Inflation Forecast Targeting. Implementing and Monitoring Inflation Targets", European Economic Review, 41, pp. 1111-1147.

Taylor J.B. (1993), "Discretion Versus Policy Rules in Theory and Practice", Carnegie-Rochester Conference Series on Public Policy, 39, pp. 195-214.

Taylor J.B. (ed.) (1999), Monetary Policy Rules. Chicago, University of Chicago Press.

Taylor J. B. (2000), "Teaching Modern Macroeconomics at the Principles Levels", Papers and Proceedings of the American Economic Associations, American Economic Review, 90, pp.90-94.

Taylor J.B., Solow R.M. (1998), Inflation, Unemployment and Monetary Policy, Cambridge (Mass), MIT Press.

Van der Ploeg F. (2005), "Back to Keynes?", CEPR, Discussion Paper Series, no.4897.

Wicksell K. (1898), Interest and Prices, London, Macmillan, 1936.

Wicksell K. (1907), "The Influence of the Rate of Interest on Prices", Economic Journal, 17, pp. 213-220.

Woodford M. (2001), "The Taylor Rule and Optimal Monetary Policy", Princeton University, mimeo.

Woodford M. (2003). Interest and Prices. Foundations of a Theory of Monetary Policy, Princeton, Princeton University Press. 


\section{Appendix}

This Appendix contains the analytical solutions of the various systems of linear dynamic equations used in the main text. Let us start with the initial structural model, which is reproduced here for convenience:

$$
\begin{aligned}
& y_{t+1}=(1-\rho) y+\rho y_{t}-\alpha\left(i_{t}-\pi_{t+1}^{e}-r\right) \\
& \pi_{t+1}=\pi+\beta\left(y_{t+1}-y\right) \\
& \pi_{t+1}^{e}=\pi_{t+1}
\end{aligned}
$$

The model is closed by an additional linear dynamic equation for the nominal interest rate $i_{t}$. Presented below is the system's solution for each specification of this equation treated in the text.

\section{A.1. The Wicksellian bank mechanism}

In this pargraph I first introduce the general solution method used in all subsequent cases. Let us consider the following equation for the nominal interest rate:

$$
i_{t}=i_{t-1}+\gamma\left(\pi_{t}-\pi\right)
$$

Addition of this interest-rate equation to system (1)-(3) and algebraic substitutions yield a two-equations homogeneous system in the "gaps" $g^{y}{ }_{t+1} \equiv y_{t+1}-y, g_{t+1}^{i} \equiv i_{t+1}-i$. In matrix form:

$$
\mathbf{g}_{t+1}=\mathbf{A} \mathbf{g}_{t}
$$

where $\mathbf{g}_{t}^{\prime} \equiv\left[g_{y t}, g_{i t}\right]$, A is the following coefficient matrix:

$$
\mathbf{A}=\left[\begin{array}{cc}
\rho^{\prime} & -\alpha^{\prime} \\
\gamma \beta \rho^{\prime} & 1-\gamma \beta \alpha^{\prime}
\end{array}\right]
$$

and

$$
\rho^{\prime} \equiv \frac{\rho}{1-\alpha \beta}, \alpha^{\prime} \equiv \frac{\alpha}{1-\alpha \beta}
$$

Given the non-zero matrix (I - A $)^{-1}$, system (A6) has steady-state solutions $\overline{\mathbf{g}}=\mathbf{0}$, i.e. $\bar{y}=y, \bar{i}=i \equiv r+\pi$, which imply, $\bar{\pi}=\pi$

Matrix A can then be used to examine the convergence and stability properties of the system. For economic reasons, we want to study conditions of monotonic stability. This reqires the characteristic 
equation of matrix $\mathbf{A}$ to have two positive real roots smaller than 1 . The characteristic equation is given by

$$
\begin{aligned}
& \operatorname{det}(\mathbf{A}-k \mathbf{I})=0 \\
& k^{2}-\left(1+\rho^{\prime}-\gamma \beta \alpha^{\prime}\right) k+\rho^{\prime}=0
\end{aligned}
$$

Let us refer to the canonical quadratic equation

$$
k^{2}+b k+c=0
$$

The condition for real roots is

$$
b^{2}-4 c \geq 0
$$

which is satisfied for

$$
\gamma<\frac{1+\rho^{\prime}-2 \rho^{\prime 1 / 2}}{\alpha^{\prime} \beta}
$$

Since (A7) implies $b<0$, given that $c>0$, the roots are positive. Moreover, any $\gamma>0$ ensures that the largest root is smaller than $1(b>-$ $(1+c))$. Therefore, (A7) is necessary and sufficient for monotonic convergence and stability of system (A5).

\section{A.2. Dynamic LM}

Let us now consider the following interest-rate equation

$$
i_{t}=\tilde{i}+\mu_{y} \delta\left(y_{t}-y_{t-1}\right)-\delta\left(\hat{m}_{t}-\pi_{t}\right)
$$

where $\tilde{i}$ admits of two specifications: a) $i_{t-1}$, b) $i^{s}$

Under specification a), addition of equation (A8) to the structural system (A1)-(A3) introduces one dynamic exogenous variable, $\hat{m}_{t}$, so that the reduced- form system in "gaps" is

$$
\mathbf{g}_{t+1}=\mathbf{A} \mathbf{g}_{t}+\mathbf{b}\left(\hat{m}_{t}-\pi\right)
$$

Therefore, a necessary condition for the steady-state solution $\overline{\mathbf{g}}=\mathbf{0}$ is $\hat{m}_{t}$ $=\pi$. The coefficient matrix $\mathbf{A}$ of the system is

$$
\left[\begin{array}{cc}
\rho^{\prime} & -\alpha^{\prime} \\
\delta\left(\beta \rho^{\prime}-\left(1-\rho^{\prime}\right) \mu_{y}\right) & 1-\alpha^{\prime} \delta\left(\beta+\mu_{y}\right)
\end{array}\right]
$$

with characteristic equation

$$
\text { (A11) } \quad k^{2}-\left(1+\rho^{\prime}-\alpha^{\prime} \delta\left(\beta+\mu_{y}\right) k+\left(\rho^{\prime}-\alpha^{\prime} \delta \mu_{y}\right)\right.
$$

The condition for real roots is

$$
\left(1+\rho^{\prime}-\alpha^{\prime} \delta\left(\beta+\mu_{y}\right)\right)^{2}-4\left(\rho^{\prime}-\alpha^{\prime} \delta \mu_{y}\right) \geq 0
$$

and, given $\rho^{\prime}<1$, it is always satisfied for any posivite $\delta, \mu_{y}$. Then the system has two positive roots smaller than 1 provided that 


$$
\begin{aligned}
& 1+\rho^{\prime}-\alpha^{\prime} \delta\left(\beta+\mu_{y}\right)>0 \\
& \rho^{\prime}-\alpha^{\prime} \delta \mu_{y}>0 \\
& 1+\rho^{\prime}-\alpha^{\prime} \delta\left(\beta+\mu_{y}\right)>1+\rho^{\prime}-\alpha^{\prime} \delta \mu_{y}
\end{aligned}
$$

Given that $\beta>0$, the third condition is always verified. Since the second condition implies the first, it is sufficient that

$$
\text { (A12) } \quad \delta \leq \rho^{\prime} / \alpha^{\prime} \mu_{y}
$$

Specification b), $\tilde{i}=i^{s}$, introduces the additional exogenous fixed variable $i^{s}$, so that,

$$
\mathbf{g}_{t+1}=\mathbf{A} \mathbf{g}_{t}+\mathbf{B} \mathbf{x}_{t}
$$

with $\mathbf{x}_{t}^{\prime}=\left[\left(\hat{m}_{t}-\pi\right),\left(i^{s}-i\right)\right]$. Therefore we now have two necessary conditions for the steady-state solution $\overline{\mathbf{g}}=\mathbf{0}$, namely $\hat{m}_{t}=\pi, \quad i s=i$. Given these conditions, the stability and convergence conditions remain unchanged.

\section{A.3. Taylor rules}

Let us begin with "adaptive" Taylor rules, whose typical format is (A14)

$$
i_{t}=i_{t-1}+\varphi\left(y_{t}-y\right)+\theta\left(\pi_{t}-\pi\right)
$$

This interest-rate equation combined with the structural system (A1)-(A3) generates a reduced-form system in "gaps" of the same type as (A5), which therefore admits the steady-state solution $\overline{\mathbf{g}}=\mathbf{0}$. The characteristic equation of the coefficient matrix $\mathbf{A}$ in this case is

$$
k^{2}-\left(1+\rho^{\prime}-\alpha^{\prime}(\theta \beta+\varphi)\right) k+\rho^{\prime}
$$

The condition for real roots is

$$
\left(1+\rho^{\prime}-\alpha^{\prime}(\theta \beta+\varphi)\right)^{2}-4 \rho^{\prime} \geq 0
$$

and is satisfied for

$$
(\varphi+\theta \beta) \leq \frac{1+\rho^{\prime}-2 \rho^{\prime 1 / 2}}{\alpha^{\prime}}
$$

Given that $\varphi+\theta \beta>0$, (A16) also implies that the first-order coefficient in the characteristic equation is positive. Since $\rho^{\prime}>0$, we have necessarily positive roots. Finally, it is also always true that

$$
-\left(1+\rho^{\prime}-\alpha^{\prime}(\theta \beta+\varphi)\right)>-\left(1+\rho^{\prime}\right)
$$

so that the roots are smaller than 1 . Therefore, condition (A16) ensures stability and monotonic convergence. 
The "forward-looking" type of rule considered in text has the following specification:

$$
i_{t}=i+\varphi\left(y_{t}-y\right)+\theta\left(\pi_{t+1}^{e} \mid i_{t-1}-\pi\right)
$$

where $\pi^{e}{ }_{t+1} \mid i_{t-1}$ indicates the inflation forecast for time $t+1$, elaborated at time $t$, conditional upon not intervening on the nominal interest rate set at time $t-1$.

In the first place, it can be shown that this specification is consistent with the standard representation of the central bank's optimal-control problem, which in terms of "gaps" is given by

$$
\begin{aligned}
& \max L_{t}=-\sum_{t}^{\infty} \frac{1}{2}\left(g_{y t}^{2}+\sigma g_{\pi t}^{2}\right) \\
& \text { s.t. } g_{\pi t}=\beta g_{y t}
\end{aligned}
$$

where $\sigma$ measures the extent of inflation aversion.

Following the same procedure as Clarida et al. (1999), the first order condition for a maximum at any point in time yields the optimal relationship between the output and inflation gaps, i.e.

$$
g_{y t}=-\sigma \beta g_{\pi t}
$$

Substituting this expression into the structural equation for output (A1), and solving for $i_{t}$, we obtain exactly equation (A17), where, however, the parameters are no longer arbitrary but should correspond to

$$
\varphi=\rho^{\prime} / \alpha^{\prime}, \quad \theta=\sigma \beta / \alpha^{\prime}
$$

We can now examine the dynamic properties of the overall system with a "forward-looking" Taylor rule as specified above. The characteristic equation of the system is now

$$
k^{2}+\left(1+\rho^{\prime}\right) \beta^{2} \sigma k-\beta^{2} \rho^{\prime} \sigma
$$

For any $\sigma>0, \beta^{2} \rho^{\prime} \sigma>0$, the equation has two real roots, one of which, however, is necessarily negative. Consequently, monotonic convergence cannot be achieved. Stability requires the two roots to be smaller than 1 in absolute value; this condition constrains the parameter of inflation aversion in the following boundaries

$$
-1 / \beta^{2}<\sigma<\frac{1}{\left(1+2 \rho^{\prime}\right) \beta^{2}}
$$


Elenco dei papers del Dipartimento di Economia

2000.1 A two-sector model of the effects of wage compression on unemployment and industry distribution of employment, by Luigi Bonatti

2000.2 From Kuwait to Kosovo: What have we learned? Reflections on globalization and peace, by Roberto Tamborini

2000.3 Metodo e valutazione in economia. Dall'apriorismo a Friedman, by Matteo Motterlini

2000.4 Under tertiarisation and unemployment. by Maurizio Pugno

2001.1 Growth and Monetary Rules in a Model with Competitive Labor Markets, by Luigi Bonatti.

2001.2 Profit Versus Non-Profit Firms in the Service Sector: an Analysis of the Employment and Welfare Implications, by Luigi Bonatti, Carlo Borzaga and Luigi Mittone.

2001.3 Statistical Economic Approach to Mixed Stock-Flows Dynamic Models in Macroeconomics, by Bernardo Maggi and Giuseppe Espa.

2001.4 The monetary transmission mechanism in Italy: The credit channel and a missing ring, by Riccardo Fiorentini and Roberto Tamborini.

2001.5 Vat evasion: an experimental approach, by Luigi Mittone

2001.6 Decomposability and Modularity of Economic Interactions, by Luigi Marengo, Corrado Pasquali and Marco Valente.

2001.7 Unbalanced Growth and Women's Homework, by Maurizio Pugno

2002.1 The Underground Economy and the Underdevelopment Trap, by Maria Rosaria Carillo and Maurizio Pugno.

2002.2 Interregional Income Redistribution and Convergence in a Model with Perfect Capital Mobility and Unionized Labor Markets, by Luigi Bonatti.

2002.3 Firms' bankruptcy and turnover in a macroeconomy, by Marco Bee, Giuseppe Espa and Roberto Tamborini.

2002.4 One "monetary giant" with many "fiscal dwarfs": the efficiency of macroeconomic stabilization policies in the European Monetary Union, by Roberto Tamborini.

2002.5 The Boom that never was? Latin American Loans in London 18221825, by Giorgio Fodor. 
2002.6 L'economia senza banditore di Axel Leijonhufoud: le 'forze oscure del tempo e dell'ignoranza' e la complessità del coordinamento, by Elisabetta De Antoni.

2002.7 Why is Trade between the European Union and the Transition Economies Vertical?, by Hubert Gabrisch and Maria Luigia Segnana.

2003.1 The service paradox and endogenous economic gorwth, by Maurizio Pugno.

2003.2 Mappe di probabilità di sito archeologico: un passo avanti, di Giuseppe Espa, Roberto Benedetti, Anna De Meo e Salvatore Espa.

(Probability maps of archaeological site location: one step beyond, by Giuseppe Espa, Roberto Benedetti, Anna De Meo and Salvatore Espa).

2003.3 The Long Swings in Economic Understianding, by Axel Leijonhufvud.

2003.4 Dinamica strutturale e occupazione nei servizi, di Giulia Felice.

2003.5 The Desirable Organizational Structure for Evolutionary Firms in Static Landscapes, by Nicolás Garrido.

2003.6 The Financial Markets and Wealth Effects on Consumption An Experimental Analysis, by Matteo Ploner.

2003.7 Essays on Computable Economics, Methodology and the Philosophy of Science, by Kumaraswamy Velupillai.

2003.8 Economics and the Complexity Vision: Chimerical Partners or Elysian Adventurers?, by Kumaraswamy Velupillai.

2003.9 Contratto d'area cooperativo contro il rischio sistemico di produzione in agricoltura, di Luciano Pilati e Vasco Boatto.

2003.10 Il contratto della docenza universitaria. Un problema multi-tasking, di Roberto Tamborini.

2004.1 Razionalità e motivazioni affettive: nuove idee dalla neurobiologia e psichiatria per la teoria economica? di Maurizio Pugno.

(Rationality and affective motivations: new ideas from neurobiology and psychiatry for economic theory? by Maurizio Pugno.

2004.2 The economic consequences of Mr. G. W. Bush's foreign policy. Can th US afford it? by Roberto Tamborini

2004.3 Fighting Poverty as a Worldwide Goal by Rubens Ricupero

2004.4 Commodity Prices and Debt Sustainability by Christopher L. Gilbert and Alexandra Tabova 
2004.5 A Primer on the Tools and Concepts of Computable Economics by K. Vela Velupillai

2004.6 The Unreasonable Ineffectiveness of Mathematics in Economics by Vela K. Velupillai

2004.7 Hicksian Visions and Vignettes on (Non-Linear) Trade Cycle Theories by Vela K. Velupillai

2004.8 Trade, inequality and pro-poor growth: Two perspectives, one message? By Gabriella Berloffa and Maria Luigia Segnana

2004.9 Worker involvement in entrepreneurial nonprofit organizations. Toward a new assessment of workers? Perceived satisfaction and fairness by Carlo Borzaga and Ermanno Tortia.

2004.10 A Social Contract Account for CSR as Extended Model of Corporate Governance (Part I): Rational Bargaining and Justification by Lorenzo Sacconi

2004.11 A Social Contract Account for CSR as Extended Model of Corporate Governance (Part II): Compliance, Reputation and Reciprocity by Lorenzo Sacconi

2004.12 A Fuzzy Logic and Default Reasoning Model of Social Norm and Equilibrium Selection in Games under Unforeseen Contingencies by Lorenzo Sacconi and Stefano Moretti

2004.13 The Constitution of the Not-For-Profit Organisation: Reciprocal Conformity to Morality by Gianluca Grimalda and Lorenzo Sacconi

2005.1 The happiness paradox: a formal explanation from psycho-economics by Maurizio Pugno

2005.2 Euro Bonds: in Search of Financial Spillovers by Stefano Schiavo

2005.3 On Maximum Likelihood Estimation of Operational Loss Distributions by Marco Bee

2005.4 An enclave-led model growth: the structural problem of informality persistence in Latin America by Mario Cimoli, Annalisa Primi and Maurizio Pugno

2005.5 A tree-based approach to forming strata in multipurpose business surveys, Roberto Benedetti, Giuseppe Espa and Giovanni Lafratta.

2005.6 Price Discovery in the Aluminium Market by Isabel FiguerolaFerretti and Christopher L. Gilbert. 
2005.7 How is Futures Trading Affected by the Move to a Computerized Trading System? Lessons from the LIFFE FTSE 100 Contract by Christopher L. Gilbert and Herbert A. Rijken.

2005.8 Can We Link Concessional Debt Service to Commodity Prices? By Christopher L. Gilbert and Alexandra Tabova

2005.9 On the feasibility and desirability of GDP-indexed concessional lending by Alexandra Tabova.

2005.10 Un modello finanziario di breve periodo per il settore statale italiano: l'analisi relativa al contesto pre-unione monetaria by Bernardo Maggi e Giuseppe Espa.

2005.11 Why does money matter? A structural analysis of monetary policy, credit and aggregate supply effects in Italy, Giuliana Passamani and Roberto Tamborini.

2005.12 Conformity and Reciprocity in the "Exclusion Game": an Experimental Investigation by Lorenzo Sacconi and Marco Faillo.

2005.13 The Foundations of Computable General Equilibrium Theory, by K. Vela Velupillai.

2005.14 The Impossibility of an Effective Theory of Policy in a Complex Economy, by K. Vela Velupillai.

2005.15 Morishima's Nonlinear Model of the Cycle: Simplifications and Generalizations, by K. Vela Velupillai.

2005.16 Using and Producing Ideas in Computable Endogenous Growth, by K. Vela Velupillai.

2005.17 From Planning to Mature: on the Determinants of Open Source Take Off by Stefano Comino, Fabio M. Manenti and Maria Laura Parisi.

2005.18 Capabilities, the self, and well-being: a research in psychoeconomics, by Maurizio Pugno.

2005.19 Fiscal and monetary policy, unfortunate events, and the SGP arithmetics. Evidence from a growth-gap model, by Edoardo Gaffeo, Giuliana Passamani and Roberto Tamborini

2005.20 Semiparametric Evidence on the Long-Run Effects of Inflation on Growth, by Andrea Vaona and Stefano Schiavo.

2006.1 On the role of public policies supporting Free/Open Source Software. An European perspective, by Stefano Comino, Fabio M. Manenti and Alessandro Rossi. 
2006.2 Back to Wicksell? In search of the foundations of practical monetary policy, by Roberto Tamborini 
PUBBLICAZIONE REGISTRATA PRESSO IL TRIBUNALE DI TRENTO 